BMJ Paediatrics Open

\title{
Impact of neonatal resuscitation trainings on neonatal and perinatal mortality: a systematic review and meta-analysis
}

Archana Patel, ${ }^{1}$ Mahalaqua Nazli Khatib, ${ }^{2}$ Kunal Kurhe, ${ }^{1}$ Savita Bhargava, ${ }^{1}$ Akash Bang $^{3}$

To cite: Patel A, Khatib MN, Kurhe K, et al. Impact of neonatal resuscitation trainings on neonatal and perinatal mortality: a systematic review and

meta-analysis. BMJ

Paediatrics Open

2017;1:e000183. doi:10.1136/ bmjpo-2017-000183

Received 25 July 2017 Revised 4 October 2017 Accepted 6 October 2017

\section{(a) CrossMark}

${ }^{1}$ Lata Medical Research Foundation, Nagpur, Maharashtra, India ${ }^{2}$ Division of Evidence Synthesis; School of Epidemiology and Public Health \& Department of Physiology, Datta Meghe Institute of Medical Sciences, Wardha, Maharashtra, India ${ }^{3}$ Department of Paediatrics, Mahatma Gandhi Institute of Medical Sciences, Sewagram, Maharashtra, India

\section{Correspondence to}

Professor Mahalaqua

Nazli Khatib, Division of

Evidence Synthesis; School of Epidemiology and Public Health \& Department of Physiology Datta Meghe Institute of Medical Sciences Wardha Maharashtra India; nazli.786@rediffmail.com

\section{ABSTRACT}

Background Training of birth attendants in neonatal resuscitation is likely to reduce birth asphyxia and neonatal mortality. We performed a systematic review and metaanalysis to assess the impact of neonatal resuscitation training (NRT) programme in reducing stillbirths, neonatal mortality, and perinatal mortality

Methods We considered studies where any NRT was provided to healthcare personnel involved in delivery process and handling of newborns. We searched MEDLINE, CENTRAL, ERIC and other electronic databases. We also searched ongoing trials and bibliographies of the retrieved articles, and contacted experts for unpublished work. We undertook screening of studies and assessment of risk of bias in duplicates. We performed review according to Cochrane Handbook. We assessed the quality of evidence using the GRADE approach.

Results We included 20 trials with 1653805 births in this meta-analysis. The meta-analysis of NRT versus control shows that NRT decreases the risk of all stillbirths by $21 \%$ (RR $0.79,95 \% \mathrm{Cl} 0.44$ to 1.41 ), 7-day neonatal mortality by $47 \%$ (RR $0.53,95 \% \mathrm{Cl} 0.38$ to 0.73 ), 28-day neonatal mortality by $50 \%$ (RR $0.50,95 \% \mathrm{Cl} 0.37$ to 0.68 ) and perinatal mortality by $37 \%$ (RR $0.63,95 \% \mathrm{Cl} 0.42$ to 0.94$)$. The meta-analysis of pre-NRT versus post-NRT showed that post-NRT decreased the risk of all stillbirths by $12 \%$ (RR $0.88,95 \% \mathrm{Cl} 0.83$ to 0.94 ), fresh stillbirths by $26 \%$ (RR $0.74,95 \% \mathrm{Cl} 0.61$ to 0.90 ), 1 -day neonatal mortality by $42 \%$ (RR $0.58,95 \% \mathrm{Cl} 0.42$ to 0.82 ), 7 -day neonatal mortality by $18 \%$ (RR $0.82,95 \% \mathrm{Cl} 0.73$ to 0.93 ), 28-day neonatal mortality by $14 \%$ (RR $0.86,95 \% \mathrm{Cl} 0.65$ to 1.13 ) and perinatal mortality by $18 \%$ (RR $0.82,95 \% \mathrm{Cl}$ 0.74 to 0.91 ).

Conclusions Findings of this review show that implementation of NRT improves neonatal and perinatal mortality. Further good quality randomised controlled trials addressing the role of NRT for improving neonatal and perinatal outcomes may be warranted.

Trial registration number PROSPERO 2016:CRD42016043668

\section{INTRODUCTION}

Approximately a quarter of fmillion neonatal deaths worldwide are as a result of birth

\section{What is already known?}

A quarter of global neonatal deaths are due to birth asphyxia. The majority of these deaths occur in low-resource settings and are preventable.

- Neonatal resuscitation training (NRT) of birth attendants using mannequins result in improved knowledge and skills needed for resuscitation.

- Translation of NRT into improved neonatal outcomes and the effect estimates of improvements need to be re-evaluated and updated.

\section{What this study adds?}

This meta-analysis assessed the impact of NRT on stillbirths, 1-day neonatal mortality, 7-day neonatal mortality, 28-day neonatal mortality and perinatal mortality.

- NRT resulted in significant reduction in stillbirths and early neonatal mortality. However, continuum of care is needed for mortality reduction from day 7 to 28.

- Future studies also need to establish the best combination of settings, trainee characteristics and training frequency to sustain the existing effect on perinatal mortality reduction.

asphyxia. ${ }^{1}$ A large majority of these deaths occur in low-resource settings and are preventable. Approximately 5\%-10\% of newborns require some support to adapt to the extrauterine environment and to establish regular respiration. ${ }^{2}$ Simple resuscitative measures are often enough to resuscitate newborns that may even appear to be lifeless at birth. Studies have shown that essential newborn care has been effective in reducing stillbirths $(\mathrm{SB}) .^{3}$

In developing countries, measures to improve resuscitative efforts through training of basic steps of neonatal resuscitation are expected to reduce birth asphyxia and neonatal mortality. Numerous studies 
have suggested that imparting neonatal resuscitation training (NRT) to healthcare providers involved in delivery process and handling of newborns has the potential to save newborn lives in low-income and middle-income settings ${ }^{4-10}$

Improvements in knowledge and skills of trainees following training programme in resource-limited settings have been reviewed. However, the impact on perinatal mortality outcomes has not been updated in last 5 years. ${ }^{9}$ The effect estimates of mortality reduction as a result of training of healthcare providers involved in delivery process and handling of newborns needs to be updated to inform hospital administrators and policy-makers the importance of investing in NRT to sustain and improve neonatal survival. A previous systematic review and meta-analysis ${ }^{11}$ assessed knowledge, skills, neonatal morbidity, neonatal mortality in first 7 days after birth and from day 8 to 28 . However, it did not include outcomes of stlillbirth, 1-day neonatal mortality or perinatal mortality which has been included in our review.

The objective of this review is to assess the impact of NRT programme in reducing stillbirths, 1-day neonatal mortality, 7-day neonatal mortality, 28-day neonatal mortality and perinatal mortality.

\section{MATERIALS AND METHODS \\ Inclusion criteria \\ Types of studies}

We included relevant randomised, quasi-randomised controlled trials, interrupted time series studies and before-after studies regardless of language or publication status.

\section{Types of participants (population) trained}

We considered studies where NRT was provided to healthcare providers (including neonatologists, physicians, nurses, interns, midwives, traditional/communitybirth attendants, auxillary nurse midwives, village health workers, paramedics) involved in delivery process and handling of newborns in a community (home-based, rural and village clusters) or a hospital (including district hospitals, health centres, dispensaries, teaching/university hospitals, regional hospital, delivery/health centres, local hospitals and tertiary care hospital) setting.

\section{Types of interventions and comparison}

Studies in which any NRT was compared with a control group (that received no NRT) or compared with data before the study (pre-NRT vs post-NRT) were included. For this purpose, we considered any NRT programme of healthcare professionals, including the American Academy of Pediatrics' (AAP) Neonatal Resuscitation Program (NRP), Helping Babies Breathe (HBB) or any other training programme that had NRP or HBB as a clearly mentioned component of training methodology.
Types of outcomes measures

We included following outcomes in the review:

1. Stillbirths: defined as number of deaths prior to complete expulsion or extraction of products of conception from its mother.

2. Fresh stillbirth: clinically defined as those deaths with no signs of life at any time after birth and without any signs of maceration.

3. 1-day neonatal mortality: defined as number of deaths in first 24 hours of life

4. 7-day neonatal mortality: defined as number of deaths in first 7 days of life

5. Perinatal mortality: defined as number of stillbirths and deaths in the first week of life.

6. 28-day neonatal mortality: defined as number of deaths in the first 28 days of life.

\section{Search strategy}

We searched following electronic databases from inception to July 2016: MEDLINE (PubMed), The Cochrane Central Register of Controlled Trials (CENTRAL, The Cochrane Library); Education Resources Information Centre (ERIC), Web of Science, Science Citation Index and Scientific Electronic Library Online. The search strategies for PubMed and CENTRAL can be found in supplementary files S1 and S2 respectively. We also searched for ongoing trials at www.clinicaltrials.gov and www.controlled-trials.com. We searched published abstracts of conferences and examined bibliographies of retrieved articles for additional studies. We contacted and requested experts and authors in this field to provide possible unpublished work.

\section{Study selection and data extraction}

Screening of studies

Two reviewers (MNK and $\mathrm{AB}$ ) independently examined studies identified by literature search; discarded articles that did not fulfil the inclusion criteria and assessed full texts of all relevant articles for inclusion. A third reviewer (AP) resolved disagreement among the primary reviewers.

\section{Data extraction and management}

For all studies that fulfilled the inclusion criteria, two reviewers (KK, SB) extracted data (table 1 and 2). Third review author (AP) cross-checked the data and resolved discrepancies. For studies where required data was lacking or could not be calculated, we requested the corresponding author for details.

\section{Assessment of risk of bias in included studies}

Two authors (SB, KK) independently assessed risk of bias for each study using criteria suggested by Cochrane Effective Practice and Organization of Care (EPOC) $)^{12}$ and using criteria outlined in Chapter 8 of Cochrane Handbook for Systematic Reviews of Interventions. ${ }^{13}$ Disagreements were resolved by discussion with the third reviewer (MNK). 

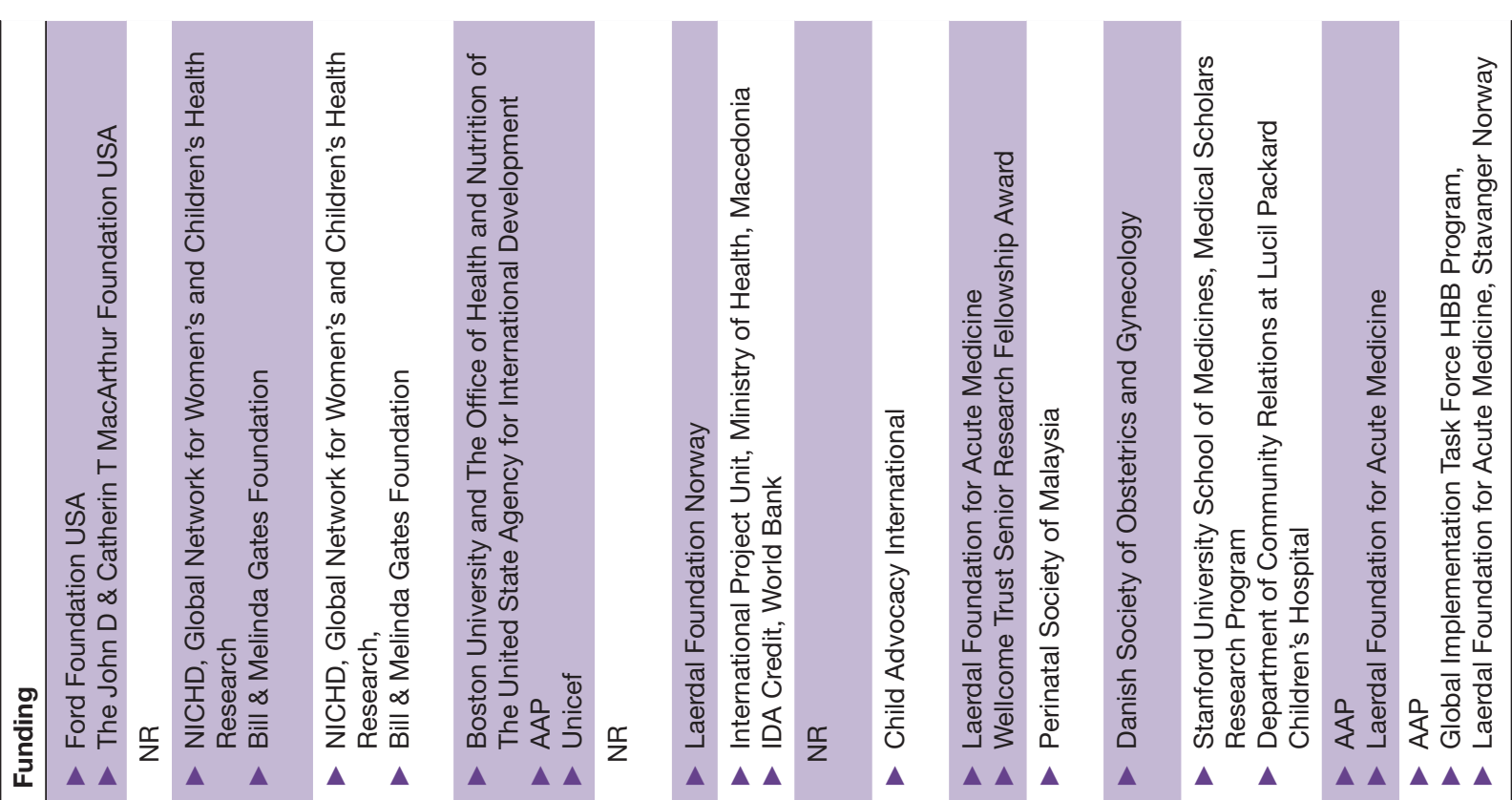

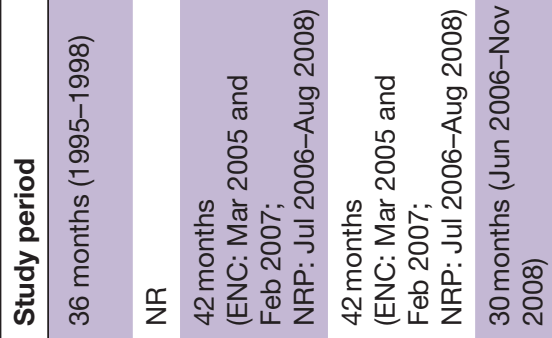

बㄹ

1
0
8

؟

可
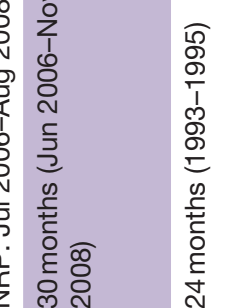

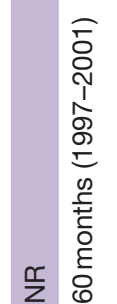

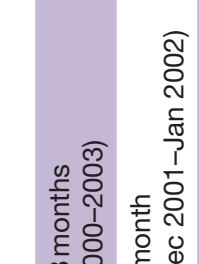

ণิ
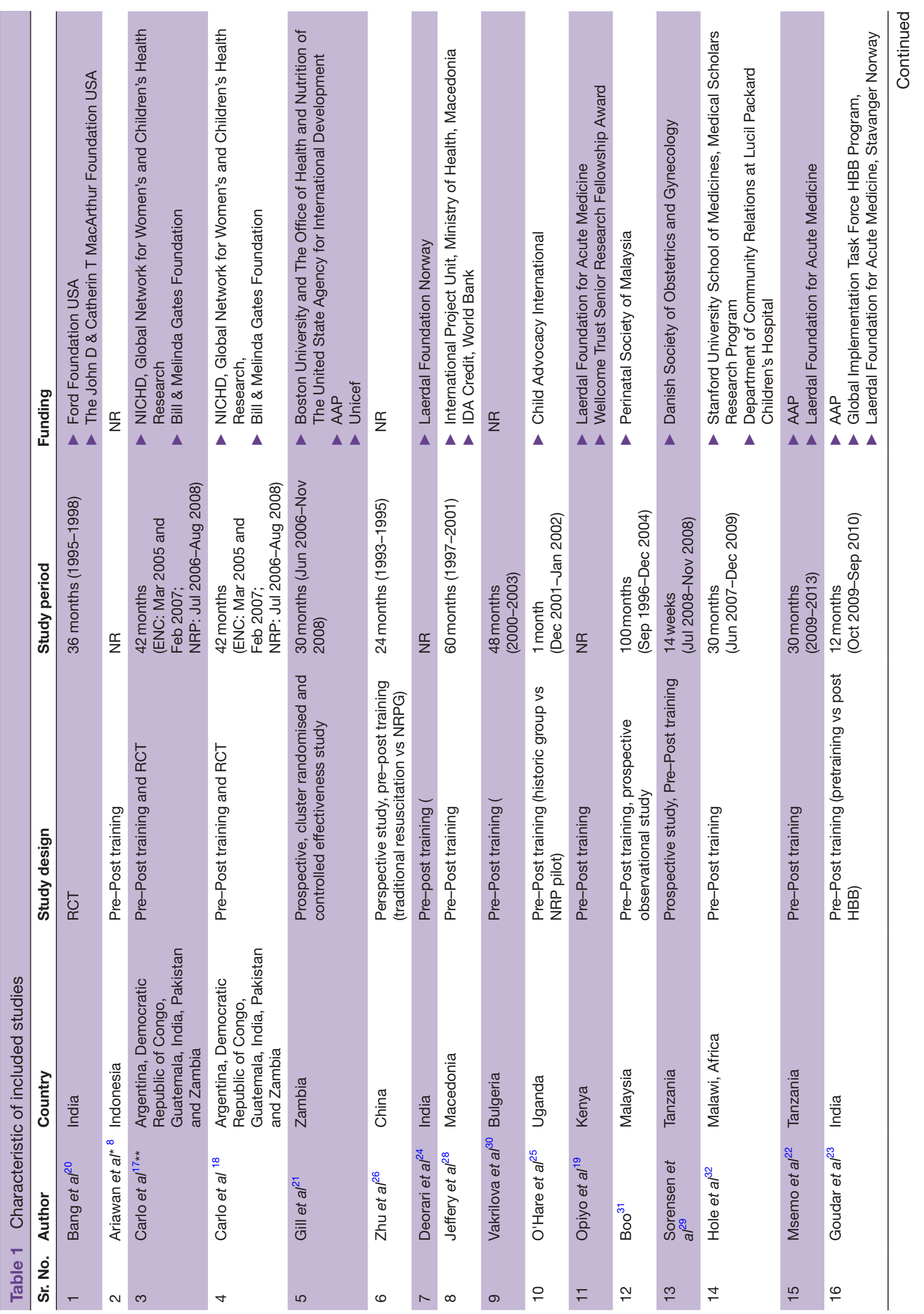


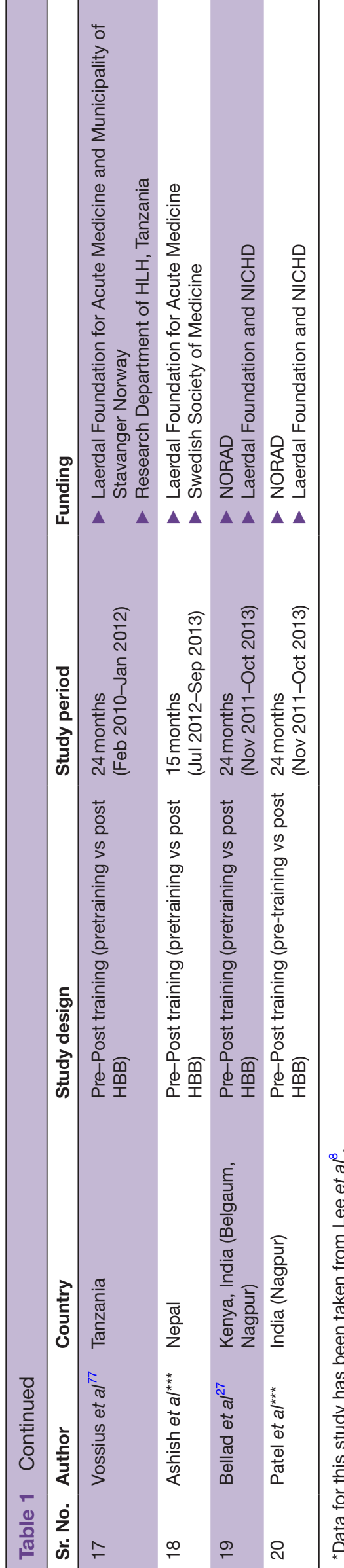

Data analysis

\section{Measures of treatment effect}

We conducted meta-analysis and reported pooled statistics as risk ratios (RR) with $95 \%$ confidence interval (CIs) for dichotomous data. We followed recommendations of the Cochrane Handbook for Systematic Reviews of Interventions Sections 9.2 and 9.4 for measuring the effects. ${ }^{13}$

Assessment of heterogeneity

We assessed heterogeneity amongst studies by inspecting forest plots for the overlap of confidence intervals, analysed statistical heterogeneity through $\mathrm{X}^{2}$ test $(\mathrm{P}$ value $>0.10$ ) and quantified through $\mathrm{I}^{2}$ statistics (Chapter 9.5 of Cochrane Handbook for Systematic Reviews) ${ }^{13} \mathrm{We}$ regarded heterogeneity as substantial if in the $\mathrm{X}^{2}$ test for heterogeneity there was either $\mathrm{I}^{2}>50 \%$, or $\mathrm{P}$ value $<0.10$. We interpreted $\mathrm{I}^{2}$ values between $0 \%$ and $40 \%$ as possibly unimportant, $30 \%$ and $60 \%$ as possibly significant, $50 \%$ and $90 \%$ as possibly substantial and $75 \%$ and $100 \%$ as possibly considerable.

\section{Assessment of reporting bias}

We used funnel plots for assessment of publication bias if ten or more studies were included in a meta-analysis.

\section{Data synthesis and analysis}

We analysed the data using Review Manager V.5.3 software. ${ }^{14}$ We conducted meta-analyses for individual studies and reported pooled statistics as relative risk (RR) between experimental and control groups with 95\% CI. We explored possible clinical and methodological reasons for heterogeneity, and in the presence of significant heterogeneity, we carried out sensitivity analysis and employed inverse-variance method with Random-effects model. We did not pool randomised and non-randomised (pre-post NRT) studies in the same meta-analysis.

\section{Summary of findings table}

We created 'summary of findings' (SoF) table using five GRADE considerations (study limitations, consistency of effect, imprecision, indirectness and publication bias) to assess the quality of a body of evidence. We used methods and recommendations described in Chapter 12 of the Cochrane Handbook for Systematic Reviews of Interventions ${ }^{13}$ using GRADEpro software ${ }^{15}$ GRADE working Group grades of evidence were used in the SoF. ${ }^{16}$

\section{RESULTS \\ Search results}

We identified 148 records through database searching and 11 records through other sources. After initial screening on the basis of title and abstract, we assessed 47 full-text articles for eligibility and finally included 20 articles in the meta-analysis. The screening details are presented in a Preferred Reporting Items for Systematic Reviews and Meta-Analyses flow diagram (figure 1). 


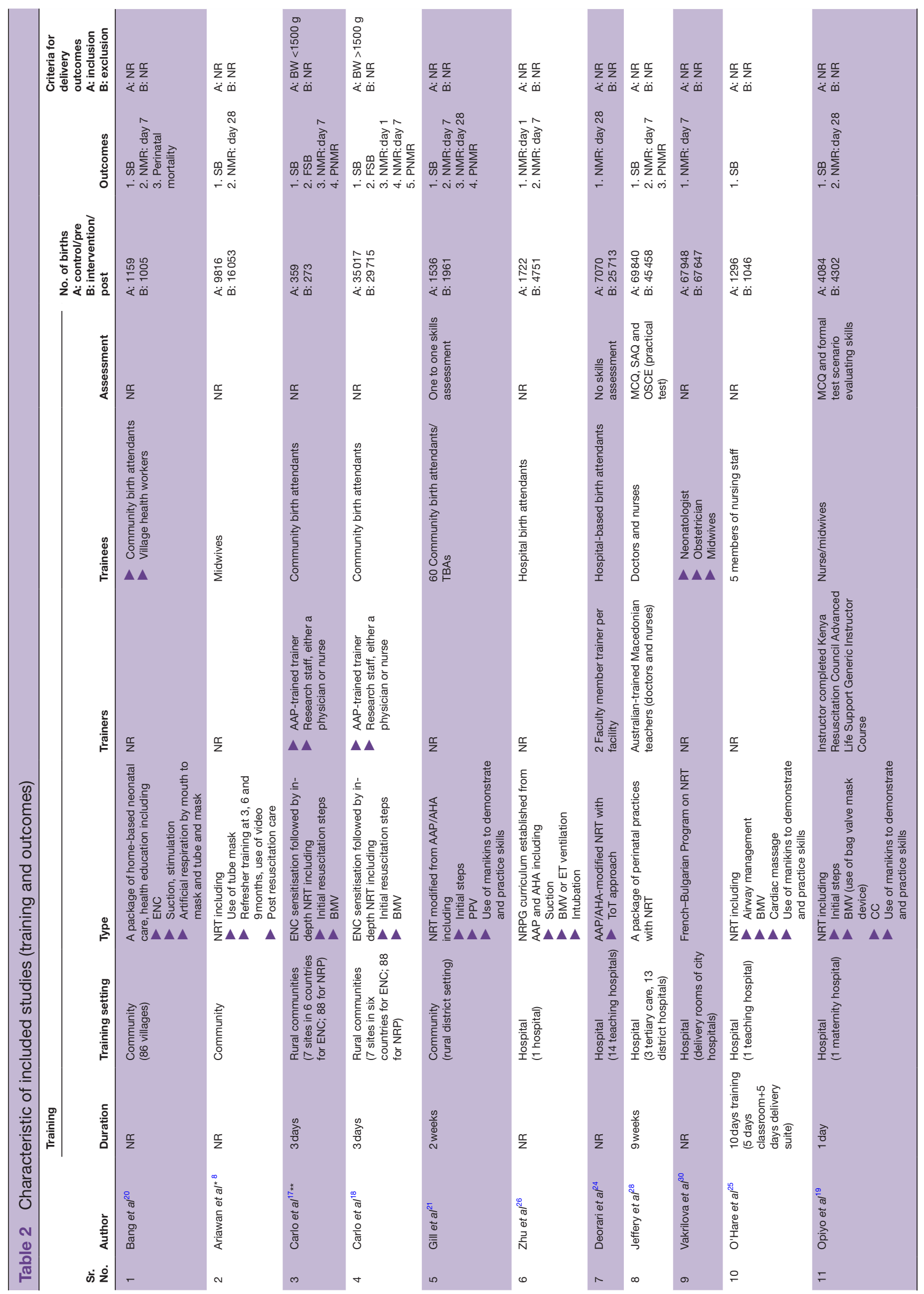

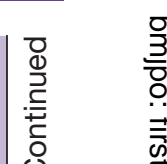



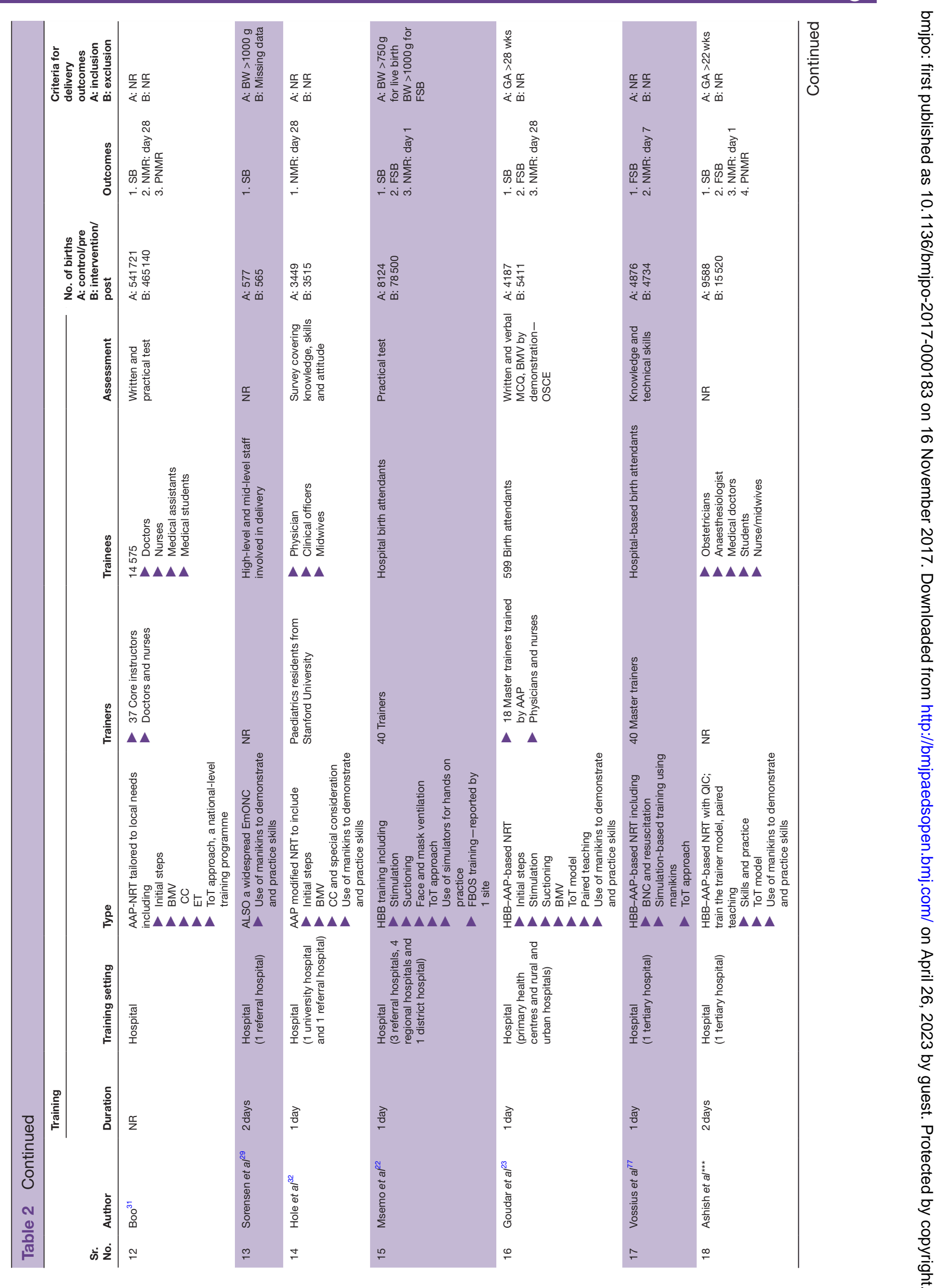


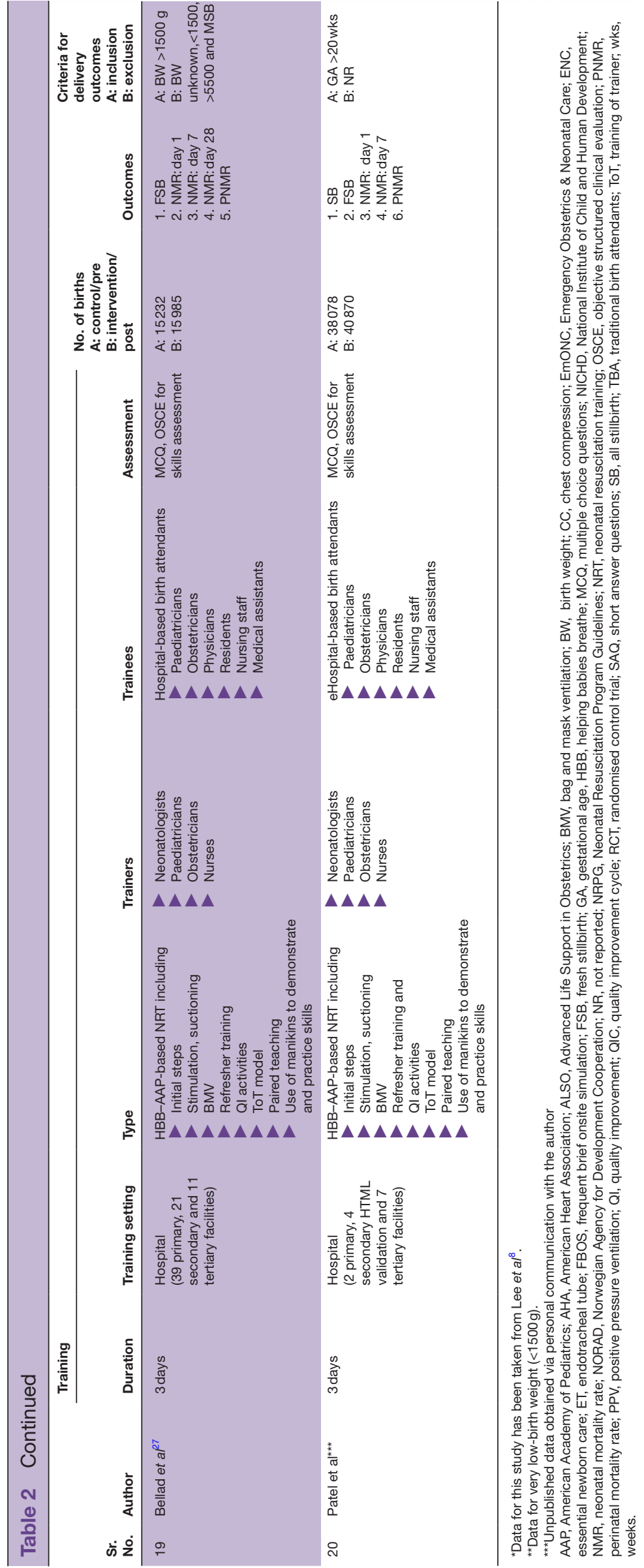

$\frac{\sigma}{3}$

$\stackrel{\vec{F}}{\stackrel{9}{9}}$

흠

$\frac{\bar{c}}{\bar{D}}$ 


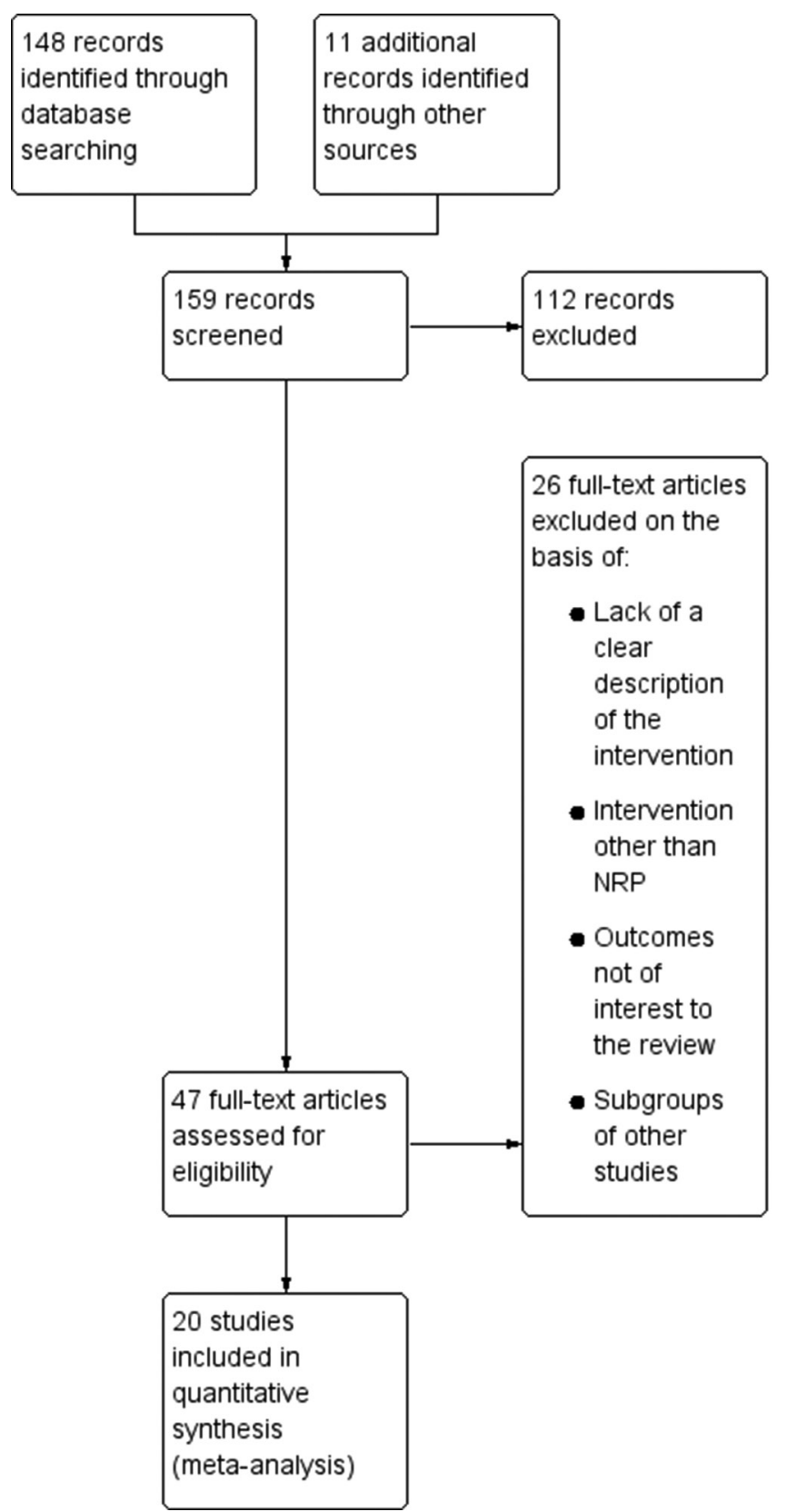

Figure 1 Flow diagram of the study selection process. NRP, Neonatal Resuscitation Program.

\section{Included studies}

Amongst included studies, two randomised trials addressed the efficacy of NRT in improving neonatal and perinatal outcomes, whereas 18 were pre-post studies. A full description of each study is included in table 1 and 2. All studies were from low-income and middle-income countries. Four studies were done in community setting, whereas 16 studies were carried in hospital setting.

Carlo et $a l^{1718}$ assessed baseline perinatal outcomes, then imparted Essential Newborn Care (ENC) training to all which also included basic steps of NRT. They then randomised all clusters that had received ENC training into two groups. One group received an in-depth NRT while the other group did not (control group). For this study we evaluated the pre-ENC outcome of all clusters

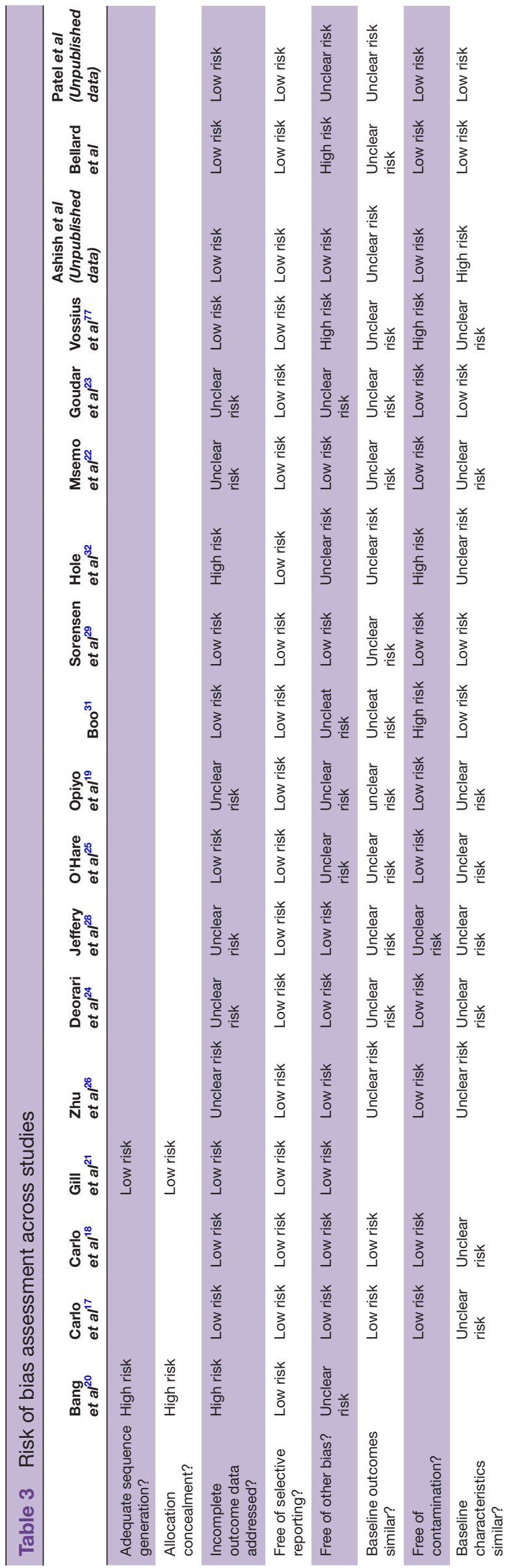




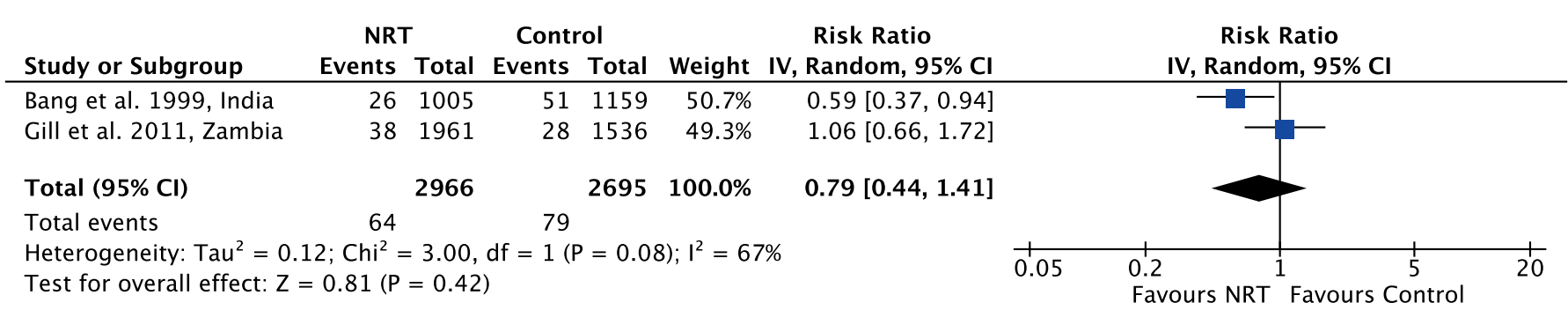

Figure 2 Forest plot comparing all SB between the NRT and the control groups. NRT, neonatal resuscitation training; SB, stillbirths.

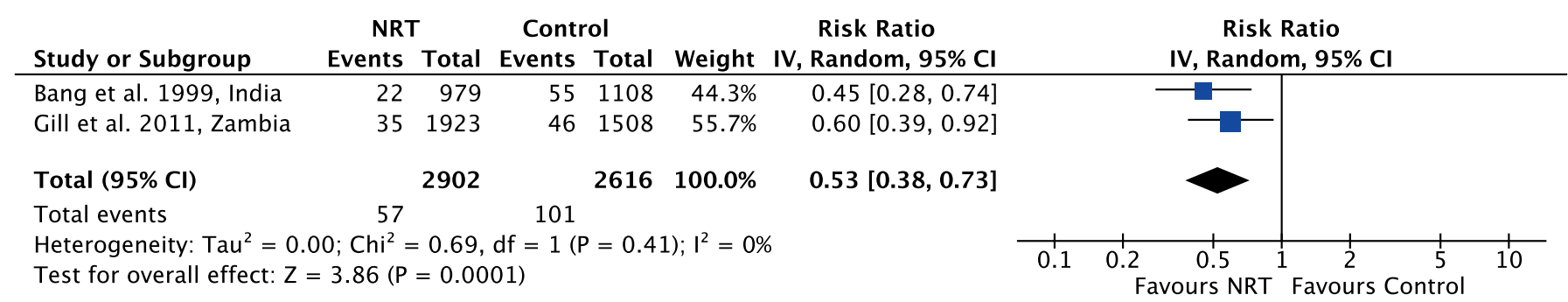

Figure 3 Forest plot comparing 7-day neonatal mortality between the NRT and the control groups. NRT, neonatal resuscitation training.

and compared them to outcomes of those clusters that received ENC + post ENC in-depth NRT. We therefore did not include this study in the NRT versus control analysis because the control group had also received NRT as a part of ENC training.

The study from Kenya had a complex design of randomisation of health workers to two groups-early training (phase I) or late training (phase II) and did not include a control group without training. ${ }^{19}$ Therefore, we analysed this study as before-after study where the rate of stillbirths prior to any training were compared with the rate of stillbirths after all phases of training.

Participants of the NRT programme differed across studies and included village health workers, community birth attendants, ${ }^{17} 18{ }^{20}$ community birth attendants/ traditional birth attendants, ${ }^{21}$ hospital-based birth attendants, ${ }^{1922-26}$ or hospital-based birth attendants including high-level and mid-level staff/specialists. ${ }^{27-34}$

Different types of training employed by studies included AAP, HBB or NRP curricula 232431323435 AAP/American Heart Association (AHA), ${ }^{2124} 26$ basic neonatal resuscitation and ENC, ${ }^{17-19} 25$ home-based neonatal care, basic training with mouth to mask or tube and mask resuscitation, ${ }^{35}$ Advanced Life Support in Obstetrics (ALSO), ${ }^{29}$
Bulgarian program on NRT. ${ }^{30}$ The duration of NRT also differed acrossstudies.

We also included two unpublished trials after permission from authors (tables 1 and 2).

\section{Excluded studies}

Studies that included interventions that did not qualify as NRT were excluded from the review. These included trainings in safe birthing techniques, ${ }^{36}$ Emergency Obstetric and Neonatal Care (EmONC), ${ }^{37} 38$ ENC, ${ }^{39-41}$ promotion of antenatal care and maternal health education, ${ }^{42}$ and newborn care intervention package. ${ }^{43}$

Other interventions that did not qualify as $\mathrm{NRT}^{44-50}$ or included interventions like neonatal intensive care unit/ special neonatal care unit training ${ }^{5152}$ were also excluded.

Studies in which desired outcomes (fetal and neonatal outcome) were not assessed, ${ }^{53-58}$ or only trainees/ training outcomes were assessed, ${ }^{59-73}$ were also excluded from the analysis.

Some studies that were subgroups of larger studies like Ersdal et $a l^{7475}$ (subgroup of Msemo et $a l^{22}$ ), Matendo et $a l^{76}$ (subgroup of Carlo et $a l^{18}$ ), Matendo et $a l^{76}$ and Vossius et $a l^{77}$ (subgroup of Msemo et $a l^{22}$ ) were also not included. However, Vossius et $a l^{77}$ was included

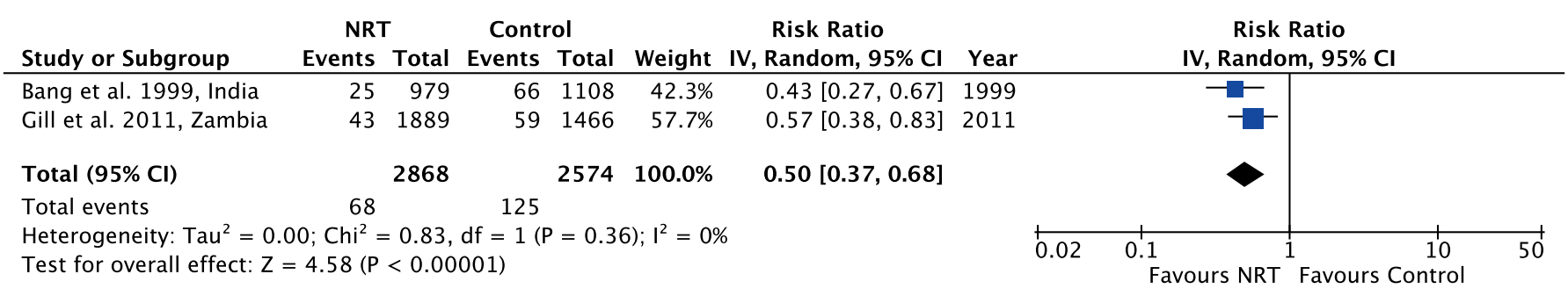

Figure 4 Forest plot comparing 28-day neonatal mortality between the NRT and the control groups. NRT, neonatal resuscitation training. 


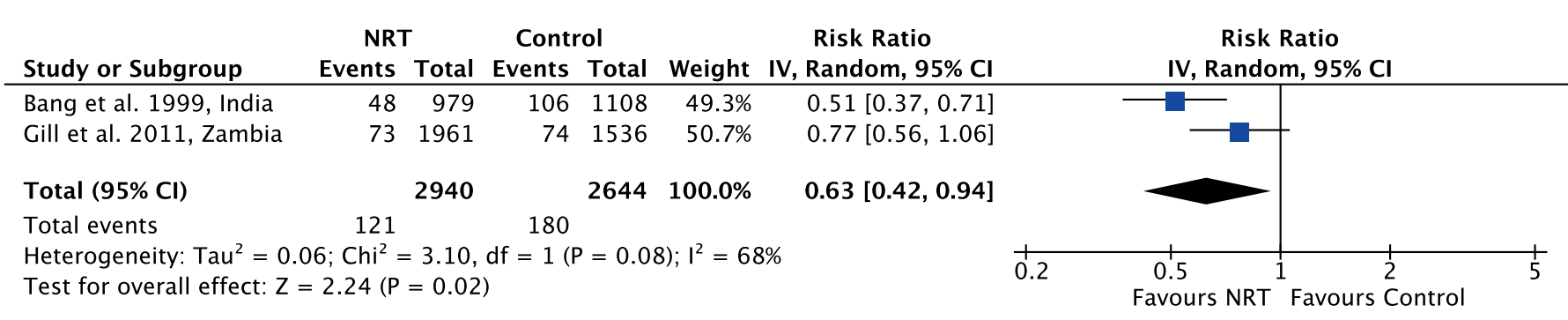

Figure 5 Forest plot comparing perinatal mortality between the NRT and the control groups. NRT, neonatal resuscitation training.

in the analysis for outcomes where data from ${ }^{22}$ Msemo et $a l^{22}$ were not available.

Risk of bias in included studies has been depicted in table 3 .

\section{Effects of interventions}

Neonatal and perinatal outcomes were reported in majority of included studies. The overall analysis showed a trend towards reduction in neonatal deaths, early neonatal deaths, perinatal deaths and stillbirths with NRT; most of which are statistically significant.

\section{NRT verses control}

The meta-analysis for NRT verses control shows that NRT decreases the risk of all stillbirths by $21 \%$ (RR 0.79 , $95 \%$ CI 0.44 to 1.41 ; participants $=5661$; studies $=2 ; \mathrm{I}^{2}=67 \%$ ) (figure 2), 7-day neonatal deaths by $47 \%$ (RR $0.53,95 \%$ CI 0.38 to 0.73 ; participants $=5518$; studies $=2 ; \mathrm{I}^{2}=0 \%$ ) (figure 3 ), 28-day neonatal deaths by $50 \%$ (RR $0.50,95 \%$ CI 0.37 to 0.68 ; participants $=5442 ;$ studies $=2 ; \mathrm{I}^{2}=0 \%$ ) (figure 4), and perinatal deaths by $37 \%$ (RR $0.63,95 \%$ CI 0.42 to
0.94; participants $=5584 ;$ studies $\left.=2 ; \quad \mathrm{I}^{2}=68 \%\right)($ figure 5). The effect was significant for ay 7-day neonatal mortality , 28-day neonatal mortality and perinatal mortality . Significant heterogeneity was observed in analysis of total stillbirths and perinatal mortality.

The grade of quality of evidence for the meta-analysis of the trials was moderate to high (table 4).

\section{Post-NRT verses pre-NRT}

The meta-analysis of post-NRT verses pre-NRT shows that post-NRT decreases the risk of all stillbirths by $12 \%$ (RR 0.88, 95\% CI 0.83 to 0.94; participants=1 425540 ; studies $=12 ; \mathrm{I}^{2}=47 \%$, figure 6 ), fresh stillbirths by $26 \%$ (RR $0.74,95 \%$ CI 0.61 to 0.90 ; participants $=296819$; studies $=8 ; I^{2}=84 \%$, figure 7 ), 1-day neonatal mortality by $42 \%$ (RR $0.58,95 \%$ CI 0.42 to 0.82 ; participants $=280080$; studies $=6 ; I^{2}=89 \%$, figure 8 ), 7-day neonatal mortality by $18 \% \quad$ (RR $0.82,95 \%$ CI 0.73 to 0.93 ; participants $=360383$; studies $=7 ; I^{2}=71 \%$, figure 9), 28-day neonatal mortality by $14 \%$ (RR $0.86,95 \%$ CI 0.65 to 1.13 ;

Table 4 Summary of findings for NRT versus control groups

\begin{tabular}{|c|c|c|c|c|c|}
\hline Outcomes & $\begin{array}{l}\text { Anticipated } \\
\text { absolute effects } \\
(95 \% \mathrm{Cl})- \\
\text { risk with no NRP }\end{array}$ & $\begin{array}{l}\text { Anticipated } \\
\text { absolute effects } \\
(95 \% \mathrm{Cl})- \\
\text { risk with NRP }\end{array}$ & $\begin{array}{l}\text { Relative effect } \\
(95 \% \mathrm{Cl})\end{array}$ & $\begin{array}{l}\text { No of participants } \\
\text { (studies) }\end{array}$ & $\begin{array}{l}\text { Quality of the } \\
\text { evidence } \\
\text { (GRADE) }\end{array}$ \\
\hline All stillbirth & 29 per 1000 & $\begin{array}{l}23 \text { per } 1000 \\
\text { (13 to } 41)\end{array}$ & $\begin{array}{l}\text { RR } 0.79 \\
\text { (0.44 to } 1.41)\end{array}$ & $\begin{array}{l}5661 \\
\text { (2 RCTs) }\end{array}$ & $\begin{array}{l}\oplus \bigcirc \bigcirc \bigcirc \\
\text { Very low* } \dagger\end{array}$ \\
\hline Fresh stillbirth & $\begin{array}{l}\text { Outcome not } \\
\text { reported }\end{array}$ & $\begin{array}{l}\text { Outcome not } \\
\text { reported }\end{array}$ & $\begin{array}{l}\text { Outcome not } \\
\text { reported }\end{array}$ & $\begin{array}{l}\text { Outcome not } \\
\text { reported }\end{array}$ & $\begin{array}{l}\oplus \bigcirc \bigcirc \bigcirc \\
\text { Very low } \ddagger\end{array}$ \\
\hline 1-day neonatal mortality & $\begin{array}{l}\text { Outcome not } \\
\text { reported }\end{array}$ & $\begin{array}{l}\text { Outcome not } \\
\text { reported }\end{array}$ & $\begin{array}{l}\text { Outcome not } \\
\text { reported }\end{array}$ & $\begin{array}{l}\text { Outcome not } \\
\text { reported }\end{array}$ & $\begin{array}{l}\oplus 000 \\
\text { Very low } \neq\end{array}$ \\
\hline 7-day neonatal mortality & 39 per 1000 & $\begin{array}{l}20 \text { per } 1000 \\
(15 \text { to } 28)\end{array}$ & $\begin{array}{l}\text { RR } 0.53 \\
\text { (0.38 to } 0.73 \text { ) }\end{array}$ & $\begin{array}{l}5518 \\
\text { (2 RCTs) }\end{array}$ & $\begin{array}{l}\oplus \oplus \oplus \oplus \\
\text { High }\end{array}$ \\
\hline 28-day neonatal mortality & 49 per 1000 & $\begin{array}{l}24 \text { per } 1000 \\
(18 \text { to } 33)\end{array}$ & $\begin{array}{l}\text { RR } 0.50 \\
(0.37 \text { to } 0.68)\end{array}$ & $\begin{array}{l}5442 \\
\text { (2 RCTs) }\end{array}$ & $\begin{array}{l}\oplus \oplus \oplus \oplus \\
\text { High }\end{array}$ \\
\hline Perinatal mortality & 68 per 1000 & $\begin{array}{l}43 \text { per } 1000 \\
\text { (29 to } 64)\end{array}$ & $\begin{array}{l}\text { RR } 0.63 \\
\text { (0.42 to } 0.94)\end{array}$ & $\begin{array}{l}5584 \\
\text { (2 RCTs) }\end{array}$ & $\begin{array}{l}\oplus \oplus \oplus \bigcirc \\
\text { Moderate§ }\end{array}$ \\
\hline
\end{tabular}

${ }^{*} \mathrm{I}^{2}$ is $67 \%$ and the two trials were inconsistent in the direction of effect. Quality of evidence downgraded by two for inconsistency and imprecision (figure 2).

†The $95 \% \mathrm{Cl}$ of the pooled estimate includes null effect. Quality of evidence downgraded by one for imprecision (figure 2). $\ddagger$ No evidence to support or refute.

$\S$ Though $\mathrm{I}^{2}$ is $68 \%$, the $95 \% \mathrm{Cl}$ of the pooled estimate does not include the null effect. Quality of evidence downgraded by one for inconsistency (figure 5).

NRT, neonatal resuscitation training; RCTs, randomised controlled trial; RR, risk ratio. 


\begin{tabular}{|c|c|c|c|}
\hline \multirow[b]{2}{*}{ Study or Subgroup } & \multicolumn{2}{|c|}{ NRT-Post } & \multirow{2}{*}{$\begin{array}{r}\mathrm{N} \\
\text { Even }\end{array}$} \\
\hline & Events & Total & \\
\hline Jeffery et al. 2004, Macedonia & 529 & 45458 & \\
\hline Ariawan et al. 2006, Indonesia & 126 & 16053 & \\
\hline O'Hare et al. 2006, Uganda & 50 & 1046 & \\
\hline Opiyo et al. 2008 , Kenya & 146 & 4302 & \\
\hline Boo et al. 2009, Malaysia & 1899 & 465140 & \\
\hline Sorensen 2010, Tanzania & 14 & 565 & \\
\hline Carlo et al. 2010,6 countries (1) & 468 & 29715 & \\
\hline Carlo et al. $2010 \mathrm{a}, 6$ countries ( 2 ) & 91 & 273 & \\
\hline Goudar et al. 2013 , India & 123 & 5411 & \\
\hline Msemo et al. 2013, Tanzania & 2546 & 78500 & \\
\hline Patel et al. 2016, India (Nagpur) (3) & 760 & 40870 & \\
\hline Ashish et al. 2016, Nepal (4) & 245 & 15520 & \\
\hline Total $(95 \% \mathrm{Cl})$ & & 702853 & \\
\hline $\begin{array}{l}\text { Total events } \\
\text { Heterogeneity: } \mathrm{Tau}^{2}=0.00 ; \mathrm{Chi}^{2}= \\
\text { Test for overall effect: } \mathrm{Z}=3.97(\mathrm{P}\end{array}$ & $\begin{array}{r}6997 \\
.78, \mathrm{df} \\
.0001)\end{array}$ & . & \\
\hline Footnotes & & & \\
\hline $\begin{array}{l}\text { (1) Carlo et al. } 2010^{18} \\
\text { (2) Carlo et al. } 2010^{17} \text {. Data for } \\
\text { (3) Unpublished data obtained vi } \\
\text { (4) Unpublished data obtained vi }\end{array}$ & . & mmun & $\begin{array}{l}\text { ants } \\
\text { ion }\end{array}$ \\
\hline
\end{tabular}

Risk Ratio

andom, 95\% Cl Yea

$0.83[0.74,0.92] 2004$

$0.85[0.65,1.11] 2006$

$1.11[0.76,1.61] 2006$

$1.19[0.94,1.52] 2008$

$0.91[0.86,0.97] 2009$

$1.43[0.64,3.19] 2010$

$0.99[0.88,1.12] 2010$

$0.76[0.62,0.94] 2010$

$0.77[0.60,0.98] 2013$

$0.88[0.78,0.99] 2013$

$0.86[0.78,0.95] 2015$

$0.76[0.63,0.92] 2016$

$0.88[0.83,0.94]$

$722687 \quad 100.0 \%$

$I^{2}=47 \%$

$8124 \quad 12.1 \%$

$38078 \quad 14.1 \%$

$7.3 \%$

$0.88[0.83,0.94]$

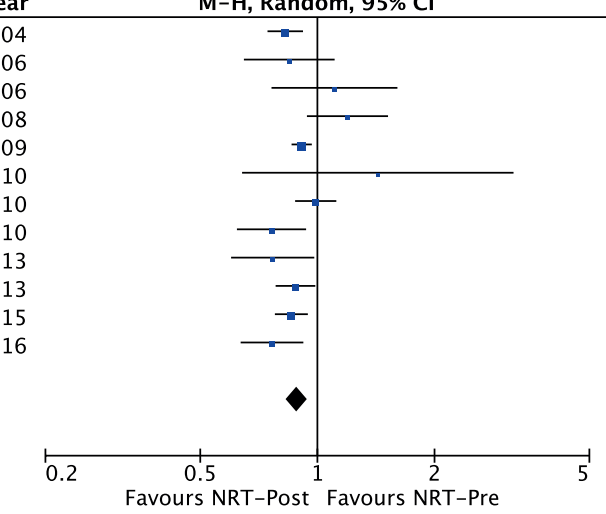

Risk Ratio
M-H, Random, 95\% C

Figure 6 Forest plot comparing all SB between the post-NRT and the pre-NRT groups. NRT, neonatal resuscitation training; $\mathrm{SB}$, stillbirths.

participants $=1116463$; studies $=7 ; \mathrm{I}^{2}=95 \%$, figure 10$)$ and perinatal mortality by $18 \%$ (RR $0.82,95 \%$ CI 0.74 to 0.91 ; participants=1 243802 ; studies $=6 ; \mathrm{I}^{2}=90 \%$, figure 11). The changes were significant in all the outcomes; except 28-day neonatal mortality. Heterogeneity was significant in all outcomes except all stillbirths. We created a funnel plot for all stillbirths, which showed asymmetry, thereby indicating a publication bias (figure 12).

The quality of evidence for NRT verses control was very low for SB and 1-day neonatal mortality, high for 7-day and 28-day neonatal mortality and moderate for perinatal mortality (table 4). The quality of evidence for post-NRT verses pre-NRT was very low for all our outcomes (table 5).

\section{DISCUSSION}

This meta-analysis assessed the impact of any NRT programme either by itself or as a part of newborn care package on rates of stillbirths, perinatal mortality, all-cause neonatal mortality on day-1, up till day-7 and till 28th day after birth. We did not evaluate intrapartum-related neonatal deaths or asphyxia/cause-specific neonatal mortality. Mortality in neonates $<7$ days of life is a proxy measure for intrapartum-related deaths. ${ }^{43} 78$ Meta-analysis of before-after studies showed a significant reduction in all stillbirths by $12 \%$ (12 studies) and of FSB by $26 \%$ ( 8 studies). The reduction in fresh stillbirths can be attributed to NRT that helps in resuscitating neonates that appear lifeless at birth. ${ }^{17} 18$ Of 12 studies, seven studies reported a significant and one study reported a non-significant reduction in fresh stillbirths. However, a non-significant increase in risk of stillbirths was reported in three African studies which blunted the impact of NRT on reduction of stillbirths.

There was reduction in 1-day mortality of $42 \%$ (6 studies) and that of 7-day mortality was $18 \%$. All studies included in the analysis (figures 8 and 9) showed a

\begin{tabular}{|c|c|c|c|c|c|c|c|c|c|c|}
\hline \multirow[b]{2}{*}{ Study or Subgroup } & \multicolumn{2}{|c|}{ NRT-Post } & \multicolumn{2}{|c|}{ NRT-Pre } & \multicolumn{3}{|c|}{ Risk Ratio } & \multirow{2}{*}{\multicolumn{3}{|c|}{$\begin{array}{c}\text { Risk Ratio } \\
\text { IV, Random, } 95 \% \mathrm{CI}\end{array}$}} \\
\hline & Events & Total & Events & Total & Weight & IV, Random, 95\% CI & Year & & & \\
\hline Opiyo et al. 2008 , Kenya & 80 & 4302 & 54 & 4084 & $10.6 \%$ & $1.41[1.00,1.98]$ & 2008 & & 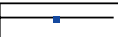 & \\
\hline Carlo et al. 2010,6 countries (1) & 336 & 29715 & 445 & 35017 & $14.7 \%$ & $0.89[0.77,1.02]$ & 2010 & & & \\
\hline Carlo et al. $2010 \mathrm{a}, 6$ countries ( 2 ) & 65 & 273 & 117 & 359 & $12.4 \%$ & $0.73[0.56,0.95]$ & 2010 & & & \\
\hline Msemo et al. 2013, Tanzania & 1131 & 78500 & 155 & 8124 & $14.3 \%$ & $0.76[0.64,0.89]$ & 2013 & & & \\
\hline Goudar et al. 2013 , India & 49 & 5411 & 70 & 4187 & $10.2 \%$ & $0.54[0.38,0.78]$ & 2013 & & & \\
\hline Patel et al. 2016, India (Nagpur) (3) & 460 & 40870 & 478 & 38078 & $14.9 \%$ & $0.90[0.79,1.02]$ & 2015 & & & \\
\hline Bellad et al. 2016, Kenya \& India (4) & 95 & 11612 & 144 & 11179 & $12.4 \%$ & $0.64[0.49,0.82]$ & 2016 & & & \\
\hline Ashish et al. 2016, Nepal (5) & 50 & 15520 & 86 & 9588 & $10.5 \%$ & $0.36[0.25,0.51]$ & 2016 & $\longrightarrow$ & & \\
\hline Total $(95 \% \mathrm{Cl})$ & & 186203 & & 110616 & $100.0 \%$ & $0.74[0.61,0.90]$ & & & & \\
\hline Total events & 2266 & & 1549 & & & & & & & \\
\hline $\begin{array}{l}\text { Heterogeneity: } \mathrm{Tau}^{2}=0.06 ; \mathrm{Chi}^{2}= \\
\text { Test for overall effect: } \mathrm{Z}=3.08(\mathrm{P}=\end{array}$ & $\begin{array}{l}52, \mathrm{df}= \\
002)\end{array}$ & $(\mathrm{P}<\mathrm{C}$ & $0001)$ & $=84 \%$ & & & & $\begin{array}{c}0.5 \\
\text { Favours Post- NRT }^{1}\end{array}$ & Favours Pr & e- NRT \\
\hline
\end{tabular}

Footnotes

(1) Carlo et al. $2010^{18}$

(2) Carlo et al. $2010^{17}$. Data for very low birth weight infants

(3) Unpublished data obtained via personnel communication

(4) Data for two sites: Kenya and India (Belgaum)

(5) Unpublished data obtained via personnel communication

Figure 7 Forest plot comparing fresh SB between the post-NRT and the pre-NRT groups. NRT, neonatal resuscitation training; SB, stillbirths. 


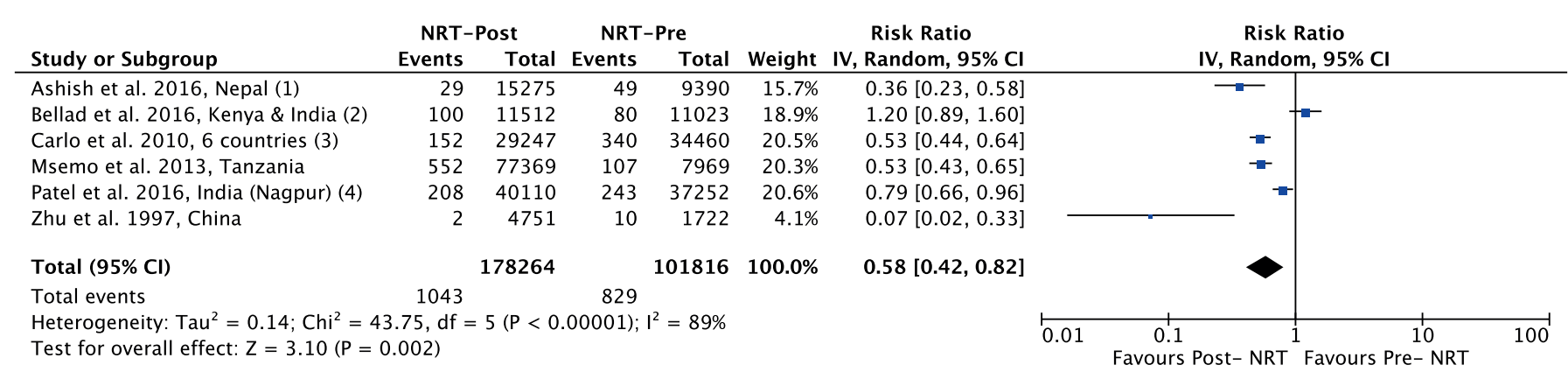

Footnotes

(1) Unpublished data obtained via personnel communication

(2) Data for two sites: Kenya and India (Belgaum)

(3) Carlo et al. 201018

(4) Unpublished data obtained via personnel communication

Figure 8 Forest plot comparing 1-day neonatal mortality between the post-NRT and the pre-NRT groups. NRT, neonatal resuscitation training.

\begin{tabular}{|c|c|c|c|c|c|c|c|c|c|c|}
\hline \multirow[b]{2}{*}{ Study or Subgroup } & \multicolumn{2}{|c|}{ NRT-Post } & \multicolumn{2}{|c|}{ NRT-Pre } & \multirow[b]{2}{*}{ Weight } & \multirow{2}{*}{$\begin{array}{c}\text { Risk Ratio } \\
\text { IV, Random, } 95 \% \mathrm{Cl} \\
\end{array}$} & \multirow{2}{*}{\multicolumn{3}{|c|}{$\begin{array}{c}\text { Risk Ratio } \\
\text { IV, Random, } 95 \% \mathrm{Cl}\end{array}$}} & \\
\hline & Events & Total & Events & Total & & & & & & \\
\hline Bellad et al. 2016, Kenya \& India (1) & 222 & 15822 & 195 & 15014 & $15.4 \%$ & $1.08[0.89,1.31]$ & & 于 & $F$ & \\
\hline Carlo et al. 2010,6 countries ( 2 ) & 543 & 29247 & 793 & 34460 & $20.2 \%$ & $0.81[0.72,0.90]$ & & -- & & \\
\hline Carlo et al. $2010 \mathrm{a}, 6$ countries ( 3 ) & 107 & 181 & 126 & 195 & $17.2 \%$ & $0.91[0.78,1.07]$ & & $\longrightarrow$ & & \\
\hline Jeffery et al. 2004 , Macedonia & 448 & 44929 & 927 & 68857 & $20.0 \%$ & $0.74[0.66,0.83]$ & & - & & \\
\hline Vakrilova et al. 2005, Bulgeria & 314 & 67647 & 367 & 67948 & $17.8 \%$ & $0.86[0.74,1.00]$ & & & & \\
\hline Vossius et al. 2014, Tanzania & 34 & 4734 & 54 & 4876 & $6.4 \%$ & $0.65[0.42,0.99]$ & & & & \\
\hline Zhu et al. 1997 , China & 16 & 4751 & 17 & 1722 & $3.0 \%$ & $0.34[0.17,0.67]$ & & & & \\
\hline Total $(95 \% \mathrm{Cl})$ & & 167311 & & 193072 & $100.0 \%$ & $0.82[0.73,0.93]$ & & & & \\
\hline Total events & 1684 & & 2479 & & & & & & & \\
\hline $\begin{array}{l}\text { Heterogeneity: } \mathrm{Tau}^{2}=0.02 ; \mathrm{Chi}^{2}= \\
\text { Test for overall effect: } \mathrm{Z}=3.00(\mathrm{P}=\end{array}$ & $\begin{array}{l}.95, \mathrm{df}= \\
.003)\end{array}$ & $6(P=0$ & $.002) ; 1^{2}=$ & $=71 \%$ & & & 0.2 & $\begin{array}{cc}0.5 & 1 \\
\text { Favours Post-NRT } & 1\end{array}$ & $\begin{array}{ll} & 1 \\
& 2 \\
\text { Favours } & \operatorname{Pr}\end{array}$ & 5 \\
\hline
\end{tabular}

Footnotes

(1) Data for two sites: Kenya and India (Belgaum)

(2) Carlo et al. $2010^{18}$

(3) Carlo et al. $2010^{17}$. Data for very low birth weight infants

Figure 9 Forest plot comparing 7-day neonatal mortality between the post-NRT and the pre-NRT groups. NRT, neonatal resuscitation training.

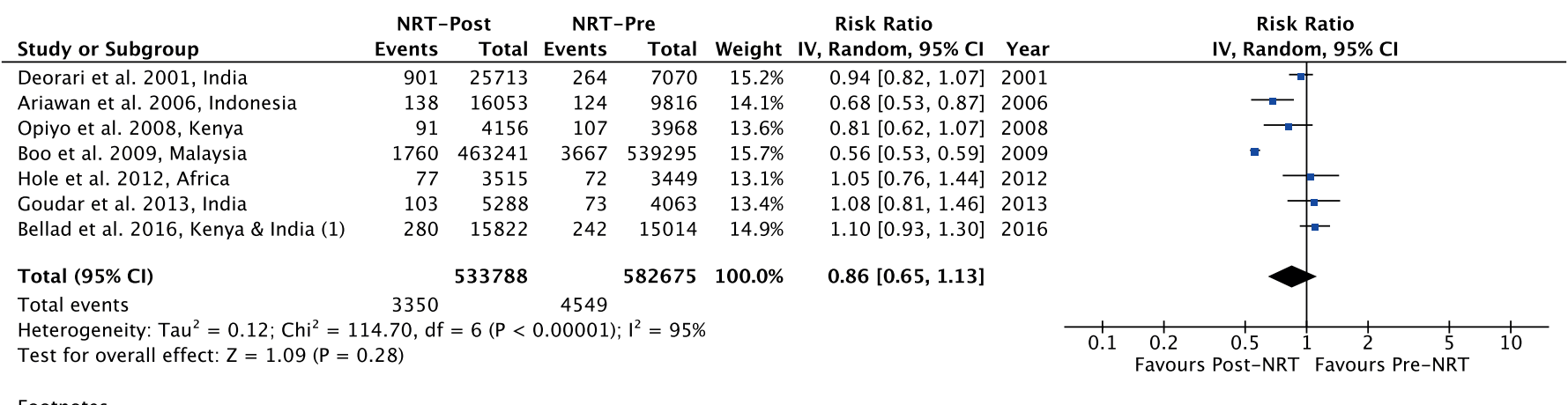

Footnotes

(1) Data for two sites: Kenya and India (Belgaum)

Figure 10 Forest plot comparing 28-day neonatal mortality between the post-NRT and the pre-NRT groups. NRT, neonatal resuscitation training.

reduction with an exception of one study. ${ }^{27}$ Failure to observe reduction in mortality in Bellad et al could be due to two reasons. First, NRT was provided in diverse health systems within a short period of time. Second, mortality was not assessed in facilities where training was imparted but was measured in the population.

The meta-analysis showed a non-significant reduction of $14 \%$ in 28-day mortality. Of the seven included studies only two studies reported a significant reduction in mortality. Resuscitation at delivery helps to reduce neonatal mortality in the first hour of birth when the neonate is at the highest risk of intrapartum-related deaths ${ }^{3}$ and the impact diminishes subsequently. For reduction of 28-day neonatal mortality, post-resuscitation specialised care for survivors is required and only NRT is unlikely to have the desired impact on 28-day neonatal mortality. ${ }^{79} 80$ 


\begin{tabular}{|c|c|c|c|}
\hline \multirow[b]{2}{*}{ Study or Subgroup } & \multicolumn{2}{|c|}{ NRT-Post } & \multirow{2}{*}{$\begin{array}{r}\text { NF } \\
\text { Even }\end{array}$} \\
\hline & Events & Total & \\
\hline Ashish et al. 2016, Nepal (1) & 362 & 15520 & \\
\hline Bellad et al. 2016, Kenya \& India (2) & 374 & 15974 & \\
\hline Boo et al. 2009, Malaysia & 3150 & 465140 & \\
\hline Carlo et al. 2010,6 countries (3) & 1011 & 29715 & \\
\hline Carlo et al. 2010a, 6 countries (4) & 198 & 272 & \\
\hline Jeffery et al. 2004, Macedonia & 977 & 45458 & \\
\hline Total $(95 \% \mathrm{Cl})$ & & 572079 & \\
\hline $\begin{array}{l}\text { Total events } \\
\text { Heterogeneity: } \mathrm{Tau}^{2}=0.01 ; \mathrm{Chi}^{2}= \\
\text { Test for overall effect: } \mathrm{Z}=3.65(\mathrm{P}=\end{array}$ & $\begin{array}{l}6072 \\
62, \mathrm{df}= \\
0003)\end{array}$ & - & 90 \\
\hline $\begin{array}{l}\text { Footnotes } \\
\text { (1) Unpublished data obtained via pe } \\
\text { (2) Data for two sites: Kenya and Ind }\end{array}$ & $\begin{array}{l}\text { sonnel co } \\
\text { (Belgaun }\end{array}$ & $\begin{array}{l}\text { ommunica } \\
\text { m) }\end{array}$ & tion \\
\hline $\begin{array}{l}\text { (3) Carlo et al. } 2010^{18} \\
\text { (4) Carlo et al. } 2010^{17} \text {. Data for ve }\end{array}$ & w bir & & \\
\hline
\end{tabular}

Figure 11 Forest plot comparing perinatal $m$ between the post-NRT and the pre-NRT groups. NRT, neonatal resuscitation training.

Trials that randomise facilities to NRT versus controls (where NRT is not a standard practice) would be ideal to assess the reduction in neonatal mortality. Trials are also likely to result in higher impact as compared with before-after studies as other changes at health facilities or in communities during the time period of before-after studies can confound the results. Because NRT is a standard practice and randomising individuals or clusters to no resuscitation training is unethical, there were only two trials available for the meta-analysis. ${ }^{2021}$ They showed a reduction of 7-day neonatal mortality and 28-day mortality by $47 \%$ (figure 3 ) and $50 \%$ (figure 4 ), respectively. The perinatal mortality reduced by $37 \%$ (figure 5 ) with no significant reduction in $\mathrm{SB}$ rates.

Previously, an expert panel published a systematic review for community-based studies and conducted a meta-analysis that evaluated whether NRT reduced all-cause neonatal mortality in th first 7 days of life. They reported a $38 \%$ reduction in mortality which is larger than the $18 \%$ (7 studies) reduction observed in the current meta-analysis. Our meta-analysis included community-based studies that resulted in a smaller effect size. Community-based studies (trials or before-after) report a smaller reduction

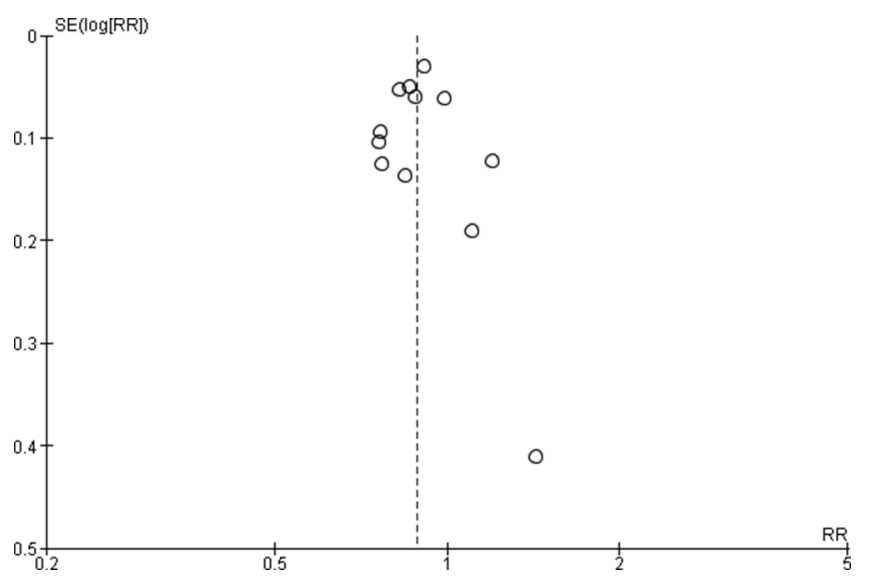

Figure 12 Funnel plot of comparison: Post-NRT verses pPre-NRT for all SB. NRT, neonatal resuscitation training; RR, risk ratio; $\mathrm{SB}$, stillbirths. effect on any day neonatal mortality. ${ }^{8171847}$ The reduction in effect size of neonatal mortality in these studies can arise due to several reasons. All births in the intervention community may not be attended by birth attendants trained in neonatal resuscitation, especially if it is a home delivery. ${ }^{81}{ }^{82}$ Second, women may decide to deliver at facilities or homes outside communities where NRT has been imparted. Finally, assessing mortality outcomes in the community can be challenging. Another meta-analysis ${ }^{11}$ was published in Cochrane which evaluated outcomes such as knowledge, skills, neonatal morbidity, neonatal mortality in first 7 days after birth and from day 8 to 28 . This analysis did not include stillbirths, 1-day neonatal mortality or perinatal mortality that was included in the current meta-analysis.

The current meta-analysis consists largely of beforeafter studies with lack of concurrent control group that limits isolation of effect of resuscitation training alone from other changes at health facilities or in communities during the time period. Other limitation is lack of consistency of settings, duration of training, varying study designs and lack of consistent outcomes which contributed to substantial heterogeneity. Lack of subgroup analysis of type of health facilities may be perceived as a limitation. An improvement in mortality would be maximised in low-resource settings with poor quality of care. However, it is presumed that there is regular training of health workers in basic resuscitation skills in higher levels of care that would translate to higher quality of care. Our recent study ${ }^{8384}$ that evaluated the knowledge and skills of trainees trained in HBB included 384 tertiary-level facilities in India. Only $3 \%$ of physicians and $5 \%$ of nurses were able to pass the pre-training bag and mask resuscitation skill assessment. ${ }^{84}$ Therefore, in the absence of reporting of pre-training skills of health workers in low-resource or high-resource settings or any indicator of quality of care, it would be erroneous to conduct a subgroup analysis based merely on resource settings and mostly will not change the results or the main message of this meta-analysis. We emphasise that despite the heterogeneity in settings, type 
Table 5 Summary of findings for Post-NRT versus Pre-NRT groups

\begin{tabular}{|c|c|c|c|c|c|}
\hline Outcomes & $\begin{array}{l}\text { Anticipated } \\
\text { absolute effects } \\
(95 \% \text { Cl) } \\
\text { Risk with } \\
\text { pre-NRP }\end{array}$ & $\begin{array}{l}\text { Anticipated absolute } \\
\text { effects }(95 \% \mathrm{Cl}) \\
\text { Risk with post-NRP }\end{array}$ & $\begin{array}{l}\text { Relative effect } \\
(95 \% \mathrm{Cl})\end{array}$ & $\begin{array}{l}\text { No of } \\
\text { participants } \\
\text { (studies) }\end{array}$ & $\begin{array}{l}\text { Quality of the } \\
\text { evidence } \\
\text { (GRADE) }\end{array}$ \\
\hline All stillbirths & 8 per 1000 & 7 per 1000 (7 to 8$)$ & RR 0.88 (0.83 to 0.94$)$ & $\begin{array}{l}1425540 \text { (12 } \\
\text { observational } \\
\text { studies) }\end{array}$ & $\begin{array}{l}\oplus \bigcirc \bigcirc 0^{* \ddagger} \\
\text { Very low }\end{array}$ \\
\hline Fresh stillbirths & 15 per 1000 & 11 per 1000 (9 to 13 ) & RR 0.74 (0.61 to 0.90$)$ & $\begin{array}{l}296819(8 \\
\text { observational } \\
\text { studies) }\end{array}$ & $\begin{array}{l}\oplus \bigcirc \bigcirc{ }^{*}{ }^{*} \\
\text { Very low }\end{array}$ \\
\hline 1-day neonatal mortality & 8 per 1000 & 5 per 1000 (4 to 7$)$ & RR 0.58 (0.42 to 0.82$)$ & $\begin{array}{l}280080 \text { (6 } \\
\text { observational } \\
\text { studies) }\end{array}$ & $\begin{array}{l}\oplus \bigcirc \bigcirc \bigcirc \\
\text { Very low *ึ }\end{array}$ \\
\hline 7-day neonatal mortality & 13 per 1000 & 11 per 1000 (9 to 12 ) & RR 0.82 (0.73 to 0.93$)$ & $\begin{array}{l}360383(7 \\
\text { observational } \\
\text { studies) }\end{array}$ & $\begin{array}{l}\oplus \bigcirc \bigcirc \bigcirc \\
\text { Very low }\end{array}$ \\
\hline $\begin{array}{l}\text { 28-day neonatal } \\
\text { mortality }\end{array}$ & 8 per 1000 & 7 per 1000 (5 to 9$)$ & RR 0.86 (0.65 to 1.13$)$ & $\begin{array}{l}1116463(7 \\
\text { observational } \\
\text { studies) }\end{array}$ & $\begin{array}{l}\oplus \bigcirc 0 \bigcirc \\
\text { Very low *t+ }\end{array}$ \\
\hline Perinatal mortality & 14 per 1000 & 12 per 1000 (10 to 13$)$ & RR 0.82 (0.74 to 0.91$)$ & $\begin{array}{l}1243802(6 \\
\text { observational } \\
\text { studies) }\end{array}$ & $\begin{array}{l}\oplus \bigcirc \bigcirc \bigcirc \\
\text { Very low * } \S \text { १ा }\end{array}$ \\
\hline
\end{tabular}

${ }^{*}$ Pre-post studies. Quality of evidence downgraded by one for risk of bias (table 1 and 2).

${ }^{\dagger}$ Studies differ in the settings, type of NRP, duration and type trainees. Quality of evidence downgraded by one for indirectness (table 1 and 2).

${ }^{\ddagger}$ Publication bias detected in the funnel plot. Quality of evidence downgraded by one for publication bias (figure 12).

${ }^{\S}$ Although $\mathrm{I}^{2}$ is $84 \%$, the effect estimates of all included studies do not differ in the direction of effect. Quality of effect downgraded by one for inconsistency (figure 7).

"Although $\mathrm{I}^{2}$ is $89 \%$, the effect estimates of all the included studies (except Bellard et al.) do not differ in the direction of effect. Quality of effect downgraded by one for inconsistency (figure 8).

${ }^{\star \star}$ Although $I^{2}$ is $71 \%$, the effect estimates of all the included studies (except Bellard et al.) do not differ in the direction of effect. Quality of effect downgraded by one for inconsistency (figure 9).

${ }^{+\dagger} \mathrm{I}^{2}$ is $95 \%$ and the effect estimates cross the life of no effect. Quality of evidence downgraded by two for inconsistency and imprecision (figure 10).

$\ddagger \ddagger T$ The effect estimate crosses the line of no effect. Quality of evidence downgraded by one for imprecision (figure 10).

${ }^{\S}$ Although $I^{2}$ is $90 \%$, the effect estimates of all the included studies do not differ in the direction of effect. Quality of effect downgraded by one for inconsistency (figure 11).

१ा Studies differ in setting, type of NRP and trainees. Quality of evidence downgraded by one for indirectness (table 1 and 2).

NRP, Neonatal Resuscitation Program; NRT, neonatal resuscitation trainings; RR, risk ratio; SB, stillbirths.

of training, type of trainees, type of trainers and the duration of training, this study showed an improvement in mortality at and soon after birth.

To conclude, NRT resulted in reduction in stillbirths and improved survival of newborns. The impact on survival of newborns can be further improved by providing a continuum of care beyond 7 days which is not addressed by NRT alone.

The meta-analysis performed showed beneficial effect of NRT in improving neonatal and perinatal outcomes. The models of training were not consistent across studies, with variations in training, trainee and setting. Generalisation of results of the pooled analysis to many currently available programme may not be appropriate. There was evidence of heterogeneity across studies in our meta-analyses; however, overall there is consistency in the direction of effect.
This review identified several important limitations of the current evidence from included studies. Due to inadequate information about the methodology followed and variety of resuscitation programmes in included studies, the quality of the evidence was downgraded for risk of bias and indirectness resulting in inability to adequately assess the effects of this intervention.

\section{CONCLUSIONS}

\section{Implications for practice}

This review shows that the implementation of NRT improves neonatal and perinatal outcomes.

\section{Implications for research}

Further good quality, multicentric randomised controlled trials addressing the role of NRT for improving neonatal and perinatal outcomes may be warranted. Impact of NRT 
on improving neonatal and perinatal outcomes as well as the best combination of settings and type of trainee should be established in future trials. More studies need to be done to assess the frequency with which NRT needs to be conducted to sustain the existing effect on perinatal mortality reduction.

Acknowledgements The authors wish to acknowledge Richard Kirubhakaran (Research Scientist, Cochrane South Asia, Prof B V Moses Centre for EvidenceInformed Healthcare \& Health Policy, Christian Medical College, Vellore) for his inputs on meta-analysis and Lauren Arlington, Partner Healthcare, for her help in getting the full text of the articles required for this review.

Contributors AP: conception of the work, design of the work, manuscript drafting with final approval of the version to be published. MNK: developed and run the search strategy, screened and selected studies, and did meta-analysis, GRADE assessment and manuscript drafting. KK and SB: involved in preparation of characteristic of studies table, data acquisition and manuscript drafting. $A B$ : screening and selection of studies, data acquisition and manuscript drafting.

Funding This work was supported by Lata Medical Research Foundation, Nagpur, India (Grant no: LMRF/GRP02/072016).

Competing interests The authors $A P$ and $A B$ were investigators in two of the studies (Bellad et al and Patel et al) included in the meta-analysis. There were no other competing interest.

Provenance and peer review Not commissioned; externally peer reviewed.

Open Access This is an Open Access article distributed in accordance with the terms of the Creative Commons Attribution (CC BY 4.0) license, which permits others to distribute, remix, adapt and build upon this work, for commercial use, provided the original work is properly cited. See: http://creativecommons.org/ licenses/by/4.0/

(C) Article author(s) (or their employer(s) unless otherwise stated in the text of the article) 2017. All rights reserved. No commercial use is permitted unless otherwise expressly granted.

\section{REFERENCES}

1. David M, Mark D. Obstetrics \& Gynaecology: an evidence-based text for MRCOG. 3rd edition. London, United Kingdom: Taylor Francis Ltd, 2010.

2. Australian resuscitation council, New Zealand resuscitation council. The resuscitation of the newborn infant in special circumstances. ARC and NZRC guideline 2010. Emerg Med Australas 2011:23:445-7.

3. Wall SN, Lee AC, Niermeyer S, et al. Neonatal resuscitation in lowresource settings: what, who, and how to overcome challenges to scale up? Int J Gynaecol Obstet 2009;107(Suppl 1):S47-S64.

4. Palme-Kilander $\mathrm{C}$. Methods of resuscitation in low-apgar-score newborn infants-a national survey. Acta Paediatr 1992;81:739-44.

5. Kattwinkel J, Niermeyer S, Nadkarni V, et al. Resuscitation of the newly born infant: an advisory statement from the pediatric working group of the international liaison committee on resuscitation. Resuscitation 1999;40:71-88.

6. International Liaison Committee on Resuscitation. The international liaison committee on resuscitation (ILCOR) consensus on science with treatment recommendations for pediatric and neonatal patients: neonatal resuscitation. Pediatrics 2006;117:e978-88.

7. Sousa S, Mielke JG. Does resuscitation training reduce neonatal deaths in low-resource communities? A systematic review of the literature. Asia Pac J Public Health 2015;27:690-704.

8. Lee AC, Cousens S, Wall SN, et al. Neonatal resuscitation and immediate newborn assessment and stimulation for the prevention of neonatal deaths: a systematic review, meta-analysis and Delphi estimation of mortality effect. BMC Public Health 2011;11:S12.

9. Reisman J, Arlington L, Jensen L, et al. Newborn resuscitation training in resource-limited settings: a systematic literature review. Pediatrics 2016;138:e20154490.

10. American heart association,american academy of pediatrics. 2005 American heart association (AHA) guidelines for cardiopulmonary resuscitation (CPR) and emergency cardiovascular care (ECC) of pediatric and neonatal patients: neonatal resuscitation guidelines. Pediatrics 2006;117:e1029-38.

11. Dempsey E, Pammi M, Ryan AC, et al. Standardised formal resuscitation training programmes for reducing mortality and morbidity in newborn infants. Cochrane Database Syst Rev 2015:CD009106 (accessed 9 Oct 2016).

12. Cochrane Effective Practice and Organisation of Care. Suggested risk of bias criteria for EPOC reviews. http://epoc.cochrane.org/sites/ epoc.cochrane.org/files/public/uploads/Resources-for-authors2017/ suggested_risk_of_bias_criteria_for_epoc_reviews.pdf (accessed 27 Sep 2017).

13. Cochrane Training. Cochrane handbook for systematic reviews of interventions. http://training.cochrane.org/handbook (accessed 8 Oct 2016).

14. The Cochrane Collaboration. Review Manager (RevMan) [Computer program]. Version 5.3. Copenhagen: The Nordic Cochrane Centre, 2014.

15. GRADEpro | GDT. GRADE's software for summary of findingstables, health technology assessmentand guidelines. https://gradepro.org/ (accessed 27 Sep 2017).

16. GRADE. GRADE handbook (SA version). http://gdt. guidelinedevelopment.org/app/handbook/handbook.html (accessed 8 Oct 2016).

17. Carlo WA, Goudar SS, Jehan I, et al. High mortality rates for very low birth weight infants in developing countries despite training Pediatrics 2010;126:e1072-e1080.

18. Carlo WA, Goudar SS, Jehan I, et al. Newborn-care training and perinatal mortality in developing countries. N Engl $\mathrm{J} \mathrm{Med}$ 2010;362:614-23.

19. Opiyo N, Were F, Govedi F, et al. Effect of newborn resuscitation training on health worker practices in Pumwani Hospital, Kenya. PLoS One 2008;3:e1599.

20. Bang AT, Bang RA, Baitule SB, et al. Effect of home-based neonatal care and management of sepsis on neonatal mortality: field trial in rural India. Lancet 1999;354:1955-61.

21. Gill CJ, Phiri-Mazala G, Guerina NG, et al. Effect of training traditional birth attendants on neonatal mortality (lufwanyama neonatal survival project): randomised controlled study. BMJ 2011;342:d346.

22. Msemo G, Massawe A, Mmbando D, et al. Newborn mortality and fresh stillbirth rates in tanzania after helping babies breathe training. Pediatrics 2013;131:e353-e360.

23. Goudar SS, Somannavar MS, Clark R, et al. Stillbirth and newborn mortality in India after helping babies breathe training. Pediatrics 2013;131:e344-e352.

24. Deorari AK, Paul VK, Singh M, et al. Impact of education and training on neonatal resuscitation practices in 14 teaching hospitals in India. Ann Trop Paediatr 2001;21:29-33.

25. O'Hare BA, Nakakeeto M, Southall DP. A pilot study to determine if nurses trained in basic neonatal resuscitation would impact the outcome of neonates delivered in Kampala, Uganda. $J$ Trop Pediatr 2006;52:376-9

26. Zhu XY, Fang HQ, Zeng SP, et al. The impact of the neonatal resuscitation program guidelines (NRPG) on the neonatal mortality in a hospital in Zhuhai, China. Singapore Med J 1997;38:485-7.

27. Bellad RM, Bang A, Carlo WA, et al. A pre-post study of a multicountry scale up of resuscitation training of facility birth attendants: does Helping Babies Breathe training save lives? BMC Pregnancy Childbirth 2016;16:222.

28. Jeffery HE, Kocova M, Tozija F, et al. The impact of evidence-based education on a perinatal capacity-building initiative in macedonia. Med Educ 2004;38:435-47.

29. Sorensen BL, Rasch V, Massawe S, et al. Impact of ALSO training on the management of prolonged labor and neonatal care at kagera regional hospital, tanzania. Int J Gynaecol Obstet 2010;111:8-12.

30. Vakrilova L, Elleau C, Slŭncheva B. [French-Bulgarian program "Resuscitation of the newborn in a delivery room"--results and perspectives]. Akush Ginekol 2005;44:35-40.

31. Boo NY. Neonatal resuscitation programme in Malaysia: an eightyear experience. Singapore Med J 2009;50:152-9.

32. Hole MK, Olmsted K, Kiromera A, et al. A neonatal resuscitation curriculum in Malawi, Africa: did it change in-hospital mortality? Int $J$ Pediatr 2012;2012:1-8.

33. Kc A, Wrammert J, Clark RB, et al. Reducing perinatal mortality in nepal using helping babies breathe. Pediatrics 2016;137:e20150117.

34. Patel A, Bang A, Kurhe $K$, et al. Impact of implementation of 'helping babies breathe (HBB)' training program on all cause and asphyxia specific mortality in selected health facilities. Unpubl Data 2013; $16: 364$

35. Bang AT, Bang RA, Tale $\mathrm{O}$, et al. Reduction in pneumonia mortality and total childhood mortality by means of community-based intervention trial in Gadchiroli, India. Lancet 1990;336:201-6.

36. O'Rourke K, Howard-Grabman L, Seoane G. Impact of community organization of women on perinatal outcomes in rural Bolivia. Rev Panam Salud Publica 1998:3:9-14. 
37. Pasha O, Goldenberg RL, McClure EM, et al. Communities, birth attendants and health facilities: a continuum of emergency maternal and newborn care (the Global Network's EmONC trial). BMC Pregnancy Childbirth 2010;10:82.

38. Pasha O, McClure EM, Wright LL, et al. A combined community- and facility-based approach to improve pregnancy outcomes in lowresource settings: a global network cluster randomized trial. BMC Med 2013;11:215.

39. Kirkwood BR, Manu A, ten Asbroek AH, et al. Effect of the newhints home-visits intervention on neonatal mortality rate and care practices in ghana: a cluster randomised controlled trial. Lancet 2013;381:2184-92.

40. Kumar V, Kumar A, Das V, et al. Community-driven impact of a newborn-focused behavioral intervention on maternal health in Shivgarh, India. Int J Gynaecol Obstet 2012;117:48-55.

41. Kumar V, Mohanty S, Kumar A, et al. Effect of community-based behaviour change management on neonatal mortality in Shivgarh, Uttar Pradesh, India: a cluster-randomised controlled trial. Lancet 2008;372:1151-62.

42. Bhutta ZA, Soofi S, Cousens S, et al. Improvement of perinatal and newborn care in rural Pakistan through community-based strategies: a cluster-randomised effectiveness trial. Lancet 2011;377:403-12.

43. Baqui AH, El-Arifeen S, Darmstadt GL, et al. Effect of communitybased newborn-care intervention package implemented through two service-delivery strategies in Sylhet district, Bangladesh: a clusterrandomised controlled trial. Lancet 2008;371:1936-44.

44. Tripathy P, Nair N, Barnett S, et al. Effect of a participatory intervention with women's groups on birth outcomes and maternal depression in jharkhand and orissa, india: a cluster-randomised controlled trial. Lancet 2010;375:1182-92.

45. Manandhar DS, Osrin D, Shrestha BP, et al. Effect of a participatory intervention with women's groups on birth outcomes in Nepal: cluster-randomised controlled trial. Lancet 2004;364:970-9.

46. Azad K, Barnett S, Banerjee B, et al. Effect of scaling up women's groups on birth outcomes in three rural districts in bangladesh: a cluster-randomised controlled trial. Lancet 2010;375:1193-202.

47. Pratinidhi A, Shah U, Shrotri A, et al. Risk-approach strategy in neonatal care. Bull World Health Organ 1986;64:291-7.

48. Daga SR, Fernandes CJ, Soares M, et al. Clinical profile of severe birth asphyxia. Indian Pediatr 1991;28:485-8.

49. Chomba E, McClure EM, Wright LL, et al. Effect of WHO newborn care training on neonatal mortality by education. Ambul Pediatr 2008;8:300-4.

50. Berglund A, Lefevre-Cholay $H$, Bacci A, et al. Successful implementation of evidence-based routines in Ukrainian maternities. Acta Obstet Gynecol Scand 2010;89:230-7.

51. Mufti P, Setna F, Nazir K. Early neonatal mortality: effects of interventions on survival of low birth babies weighing 1000-2000g. J Pak Med Assoc 2006;56:174-6.

52. Sen A, Mahalanabis D, Singh AK, et al. Impact of a district level sick newborn care unit on neonatal mortality rate: 2-year follow-up. $J$ Perinatol 2009;29:150-5.

53. Patel D, Piotrowski ZH, Nelson MR, et al. Effect of a statewide neonatal resuscitation training program on Apgar scores among high-risk neonates in Illinois. Pediatrics 2001;107:648-55.

54. Patel D, Piotrowski ZH. Positive changes among very low birth weight infant apgar scores that are associated with the neonatal resuscitation program in Illinois. J Perinatol 2002;22:386-90.

55. Draycott $\mathrm{T}$, Sibanda $\mathrm{T}$, Owen $\mathrm{L}$, et al. Does training in obstetric emergencies improve neonatal outcome? BJOG 2006;113:177-82.

56. Duran R, Görker I, Küçükuğurluoğlu Y, et al. Effect of neonatal resuscitation courses on long-term neurodevelopmental outcomes of newborn infants with perinatal asphyxia. Pediatr Int 2012;54:56-9.

57. Duran R, Aladağ N, Vatansever U, et al. Proficiency and knowledge gained and retained by pediatric residents after neonatal resuscitation course. Pediatr Int 2008;50:644-7.

58. Xu T, Wang $\mathrm{H}$, Gong $\mathrm{L}$, et al. The impact of an intervention package promoting effective neonatal resuscitation training in rural China. Resuscitation 2014;85:253-9.

59. Bookman L, Engmann C, Srofenyoh E, et al. Educational impact of a hospital-based neonatal resuscitation program in Ghana. Resuscitation 2010;81:1180-2.

60. Hoban R, Bucher S, Neuman I, et al. 'Helping babies breathe' training in sub-saharan africa: educational impact and learner impressions. J Trop Pediatr 2013;59:180-6.
61. Singhal $\mathrm{N}$, Lockyer J, Fidler $\mathrm{H}$, et al. Helping babies breathe: global neonatal resuscitation program development and formative educational evaluation. Resuscitation 2012;83:90-6.

62. Enweronu-Laryea C, Engmann C, Osafo A, et al. Evaluating the effectiveness of a strategy for teaching neonatal resuscitation in west africa. Resuscitation 2009;80:1308-11.

63. Ryan CA, Ahmed S, Abdullah H, et al. Dissemination and evaluation of AAP/AHA neonatal resuscitation programme in ireland. Ir Med $J$ 1998;91:51-2.

64. Halamek LP, Kaegi DM, Gaba DM, et al. Time for a new paradigm in pediatric medical education: teaching neonatal resuscitation in a simulated delivery room environment. Pediatrics 2000;106:e45.

65. Thomas EJ, Williams AL, Reichman EF, et al. Team training in the neonatal resuscitation program for interns: teamwork and quality of resuscitations. Pediatrics 2010;125:539-46.

66. Thomas EJ, Taggart B, Crandell S, et al. Teaching teamwork during the neonatal resuscitation program: a randomized trial. $J$ Perinatol 2007:27:409-14.

67. Couper ID, Thurley JD, Hugo JF. The neonatal resuscitation training project in rural south africa. Rural Remote Health 2005;5:459.

68. Nadel FM, Lavelle JM, Fein JA, et al. Assessing pediatric senior residents' training in resuscitation: fund of knowledge, technical skills, and perception of confidence. Pediatr Emerg Care 2000;16:73-6.

69. Nadel FM, Lavelle JM, Fein JA, et al. Teaching resuscitation to pediatric residents: the effects of an intervention. Arch Pediatr Adolesc Med 2000;154:1049-54.

70. Kurosawa $\mathrm{H}$, Ikeyama T, Achuff $\mathrm{P}$, et al. A randomized, controlled trial of in situ pediatric advanced life support recertification ("pediatric advanced life support reconstructed") compared with standard pediatric advanced life support recertification for ICU frontline providers*. Crit Care Med 2014;42:610-8.

71. Ergenekon E, Koç E, Atalay $\mathrm{Y}$, et al. Neonatal resuscitation course experience in turkey. Resuscitation 2000:45:225-7.

72. Quan L, Shugerman RP, Kunkel NC, et al. Evaluation of resuscitation skills in new residents before and after pediatric advanced life support course. Pediatrics 2001;108:e110.

73. Curran V, Fleet L, White S, et al. A randomized controlled study of manikin simulator fidelity on neonatal resuscitation program learning outcomes. Adv Health Sci Educ Theory Pract 2015;20:205-18.

74. Ersdal HL, Vossius C, Bayo E, et al. A one-day "helping babies breathe" course improves simulated performance but not clinical management of neonates. Resuscitation 2013;84:1422-7.

75. Ersdal HL, Singhal N. Resuscitation in resource-limited settings. Semin Fetal Neonatal Med 2013;18:373-8.

76. Matendo R, Engmann C, Ditekemena J, et al. Reduced perinatal mortality following enhanced training of birth attendants in the democratic republic of congo: a time-dependent effect. BMC Med 2011;9:93.

77. Vossius C, Lotto E, Lyanga S, et al. Cost-effectiveness of the "helping babies breathe" program in a missionary hospital in rura Tanzania. PLoS One 2014;9:e102080.

78. Edmond KM, Quigley MA, Zandoh C, et al. Aetiology of stillbirths and neonatal deaths in rural Ghana: implications for health programming in developing countries. Paediatr Perinat Epidemiol 2008;22:430-7.

79. Darmstadt GL, Bhutta ZA, Cousens S, et al. Evidence-based, costeffective interventions: how many newborn babies can we save? Lancet 2005:365:977-88.

80. Bhutta ZA, Darmstadt GL, Hasan BS, et al. Community-based interventions for improving perinatal and neonatal health outcomes in developing countries: a review of the evidence. Pediatrics 2005;115:519-617.

81. Kumbani L, Bjune G, Chirwa E, et al. Why some women fail to give birth at health facilities: a qualitative study of women's perceptions of perinatal care from rural southern malawi. Reprod Health 2013;10:9.

82. Yakoob MY, Menezes EV, Soomro T, et al. Reducing stillbirths: behavioural and nutritional interventions before and during pregnancy. BMC Pregnancy Childbirth 2009;9:S3.

83. Bang A, Bellad R, Gisore P, et al. Implementation and evaluation of the helping babies breathe curriculum in three resource limited settings: does helping babies breathe save lives? a study protocol. BMC Pregnancy Childbirth 2014;14:116.

84. Bang A, Patel A, Bellad R, et al. Helping Babies Breathe (HBB) training: What happens to knowledge and skills over time? BMC Pregnancy Childbirth 2016;16:364. 